\title{
Proposta de aplicação da abordagem Quick Response Manufacturing (QRM) para a redução do lead time em operações de escritório
}

\author{
Andrey Domingues de Lima ${ }^{a *}$, Stella Jacyszyn Bachega ${ }^{b}$, Moacir Godinho Filhoc, \\ Valcir de Jesus Sousa da $\mathrm{Cruz}^{\mathrm{d}}$, Jacqueline Martins Rossi ${ }^{\mathrm{e}}$ \\ a*andreydomingues@yahoo.com.br, UFSCar, Brasil \\ bstella.bachega@catalao.ufg.br, UFG, Brasil \\ 'moacir@dep.ufscar.br, UFSCar, Brasil \\ dsousa_cruz@superig.com.br, UFSCar, Brasil \\ ejmrossi@toyota.com.br, UFSCar, Brasil
}

\begin{abstract}
Resumo
A administração eficiente e eficaz do lead time pode criar vantagens competitivas para as empresas. Uma abordagem que possui a preocupação de reduzir o lead time é a Manufatura de Resposta Rápida (QRM - Quick Response Manufacturing). 0 objetivo do presente trabalho é propor a aplicação de princípios e técnicas do QRM para redução do lead time do processo de orçamentação de uma empresa fabricante de materiais de escrita situada no Brasil. Para tanto, utilizou-se a pesquisa teórico-conceitual e o estudo de caso como procedimentos de pesquisa. Verificou-se que a empresa estudada poderá obter vantagens significativas com a adoção desta abordagem. Os resultados esperados por meio da implantação da proposta mostram uma redução de $38,1 \%$ no lead time total do processo de orçamentação da empresa estudada. Esse artigo contribui para maior divulgação e compreensão da abordagem QRM e de seus benefícios.
\end{abstract}

Palavras-chave

Manufatura de resposta rápida. Lead time. Operações de escritório. Orçamentação.

\section{Introdução e objetivos do trabalho}

A administração do tempo, especificamente do lead time, pode ser uma importante vantagem competitiva. Segundo Porter (2003) e Mason-Jones e Towill (1999), o lead time é o indicador de mercado que alavanca significativamente as métricas fundamentais da empresa. Nesse trabalho, lead time é definido, de acordo com Ericksen, Stoflet e Suri et al. (2007), como sendo o tempo típico - medido em dias corridos - desde que o cliente faz o pedido, passando pelo caminho crítico, até que a primeira peça do pedido seja entregue ao cliente.

Conforme Tersine e Hummingbird (1995), para controlar o lead time, o primeiro passo é a análise da situação atual. 0 fluxo de material e informação deve ser identificado e o lead time separado em vários elementos e componentes. A administração do tempo é espelhada na gestão da qualidade, custo, inovação e produtividade. Geralmente, perde-se tempo por causa da execução sequencial de atividades independentes, pela falta de sincronização de atividades dependentes, pela produção de itens que são rejeitados ou retrabalhados, ou pelo fluxo ineficiente de trabalho.

Lead time tem sido um problema histórico na manufatura. Perry (1990) e Schmenner (1991) identificaram vários fatores que contribuem para lead times excessivos na manufatura. Wieters (1979) notou que as maiores consequências de lead times excessivos são problemas de programação e expedições dispendiosas. Trabalhos recentes com a preocupação de redução de lead time são: Fahimnia, 
Marian e Motevallian (2009), Leng e Parlar (2009), Bottani e Rizzi (2008), Parveen e Rao (2008), Bertolini et al. (2007), Ouyang, Chuang e lin (2007) e Song e Ming (2006).

Alguns paradigmas de produção possuem a preocupação com a redução do lead time, por exemplo, a Manufatura Enxuta, a Competição Baseada no Tempo (TBC - Time Based Competition) e a Manufatura Ágil. A abordagem denominada Manufatura de Resposta Rápida (QRM - Quick Response Manufacturing), proposta por Suri (1998), também possui essa preocupação. As vantagens do QRM estão presentes na introdução de produtos no mercado, na produção já existente, na implantação de estratégias de resposta rápida, na aquisição de ordens, na identificação de desperdícios devidos ao lead time longo e entregas atrasadas e, também, na prevenção deles. No entanto, a implementação do QRM requer encontrar novos caminhos para realizar um trabalho com ênfase na redução do lead time.

0 QRM também pode ser aplicado em operações de escritório. Nesse trabalho, operações de escritório são definidas como sendo todas as atividades necessárias para o processamento de um pedido que não ocorrem especificamente no chão de fábrica. Dessa forma, exemplos de atividades no escritório são: processamento de cotações, processamento dos pedidos, atividades de engenharia, orçamentação, planejamento e programação da produção, contratação de funcionários, dentre outras. Conforme Suri (1998), as operações de escritório representam oportunidades para desenvolver vantagens competitivas.

Com base nesse contexto, surgiu a seguinte questão de pesquisa: Qual a contribuição esperada da aplicação da abordagem QRM na redução do lead time das operações de escritório de uma empresa que fabrica materiais de escrita? 0 problema desta pesquisa baseia-se na premissa de que a redução do lead time é necessária em todas as atividades da empresa, inclusive nas operações de escritório, para assim, o objetivo empresarial ser atingido o mais breve possível.

O QRM, apesar de ser um método bastante divulgado e aplicado na prática em empresas ao redor do mundo, ainda é pouco conhecido no Brasil. Assim, o presente trabalho possui o objetivo de propor a aplicação da abordagem QRM para redução do lead time do processo de orçamentação de uma empresa que fabrica materiais de escrita (lápis de cor e grafite, canetas, lapiseiras etc.) situada no Brasil. Orçamento, de acordo com Westwood (1991), é um plano que considera a expectativa de vendas da empresa em determinado período e o investimento nos recursos necessários para obter o resultado desejado. Para Gitman (2004), o processo de orçamentação envolve a avaliação e seleção de investimentos a longo prazo, sendo estes coerentes com os objetivos de maximização da riqueza dos proprietários da empresa.

Ademais, Brian (2007) e Herkommer e Herkommer (2006) mostram a importância em se focar operações de escritório para a obtenção de melhorias em empresas, tema esse que vem ganhando muita importância nos dias atuais, com ferramentas tais como o Lean Office (TAPPING; SHUKER, 2003).

Para cumprir o objetivo, este artigo segue a seguinte estrutura: na segunda seção é mostrado um breve referencial teórico a respeito da abordagem QRM; na terceira seção é mostrada a metodologia de pesquisa empregada no trabalho; na quarta seção é explicitado o estudo de caso realizado; na quinta seção há a análise dos princípios e técnicas do QRM propostos na empresa; e na sexta seção estão as considerações finais deste trabalho.

\section{0 Quick Response Manufacturing (QRM)}

Quick Response Manufacturing (QRM) é definido por Suri (1998) como sendo uma estratégia voltada para a redução do lead time em todas as operações de uma empresa. Essa abordagem, já aplicada com sucesso na prática em mais de 200 empresas nos Estados Unidos e Europa (UNIVERSITY..., 2009), também começa a ganhar espaço na literatura internacional sobre Gestão da Produção, sendo citada e referenciada em inúmeros trabalhos: Hopp e Spearman (2007), Fernandes e Carmo-Silva (2006), Treville, Shapiro e Hameri (2004) etc. Também, nacionalmente o tema vem ganhando certa importância, como mostram os trabalhos de Godinho Filho e Uzsoy (2009), Sellitto et al. (2008), Saes e Godinho Filho (2008), dentre outros.

Basicamente, o QRM propõe que a redução do lead time seja feita por meio da implementação de um projeto que segue uma metodologia de implantação específica composta por quatro fases: definição do problema, coleta e análise de dados, proposta de melhorias utilizando os princípios e técnicas do QRM e análise dos resultados esperados.

Referente às etapas de definição do problema e coleta e análise de dados, tem-se que o QRM utiliza uma série de técnicas e métodos costumeiramente empregados em trabalhos de Engenharia de Produção (tais como ferramentas da qualidade, simulação discreta, dentre outros), bem como de métodos propostos por Suri (1998) para serem utilizados dentro do escopo da abordagem do QRM. 0 Quadro 1 mostra as principais técnicas e métodos de coleta e análise de dados utilizados pela abordagem QRM. 
Quadro 1. Principais Métodos e Técnicas de coleta e análise de dados utilizados pela abordagem QRM.

\begin{tabular}{|c|c|c|c|}
\hline Método/Técnica & Descrição & $\begin{array}{l}\text { Uso proposto } \\
\text { por Suri } \\
\text { (1998) }\end{array}$ & $\begin{array}{l}\text { Uso } \\
\text { costumeiro em } \\
\text { trabalhos de } \\
\text { Engenharia de } \\
\text { Produção }\end{array}$ \\
\hline $\begin{array}{l}\text { Mapeamento } \\
\text { do processo/ } \\
\text { Manufacturing } \\
\text { Critical-path } \\
\text { Time (MCT) }\end{array}$ & $\begin{array}{l}\text { Mostra um mapa interfuncional que fornece uma visão de como o trabalho } \\
\text { ocorre; isso fornece um meio fácil para todos entenderem o processo. Esta } \\
\text { ferramenta deve fornecer também o lead time do processo e auxiliar comparações } \\
\text { antes e pós-sugestões de melhorias. O MCT é a típica quantidade de tempo } \\
\text { medida a partir da criação de uma ordem, passando pelo caminho crítico até } \\
\text { que a primeira peça única desta ordem seja entregue ao cliente (ERICKSEN; } \\
\text { STOFLET; SURl, 2007). }\end{array}$ & $x$ & \\
\hline Tagging & $\begin{array}{l}\text { Técnica que envolve anexar documentos a cada tarefa a fim de que este } \\
\text { documento siga a tarefa por todo o seu processo. Ao longo do processo, dados } \\
\text { são coletados sobre a duração de cada etapa, a quantidade de tempo em trânsito, } \\
\text { os tempos que agregam e os que não agregam valor. Um ponto importante sobre } \\
\text { o tagging é que os dados são utilizados para analisar o sistema como um todo e } \\
\text { não uma pessoa ou departamento. }\end{array}$ & $x$ & \\
\hline $\begin{array}{l}\text { Gráfico de Valor } \\
\quad \text { agregado }\end{array}$ & $\begin{array}{l}\text { Gráfico que divide o lead time total de um processo (em dias corridos, contando } \\
\text { fins de semana e feriados) em tempos que agregam valor (referentes às atividades } \\
\text { do processo que o cliente está disposto a pagar por elas) e outros tempos. Este } \\
\text { gráfico é de suma importância para o QRM, pois ajuda a identificar o que está } \\
\text { acontencendo hoje na empresa e quais são as possibilidades de melhoria. }\end{array}$ & $x$ & \\
\hline $\begin{array}{l}\text { Simulação e } \\
\text { modelagem de } \\
\text { capacidade }\end{array}$ & $\begin{array}{l}\text { É fundamental, mesmo em operações de escritório. Várias ferramentas podem } \\
\text { ser utilizadas, como já visto anteriormente, dentre elas softwares de simulação, } \\
\text { softwares de modelagem rápida (RMP - Rapid Modeling Technique), segundo } \\
\text { Suri (1989) e Treville (1994), ou mesmo uma planilha eletrônica. }\end{array}$ & $x$ & $x$ \\
\hline $\begin{array}{l}\text { Ferramentas do } \\
\text { TQM (Total Quality } \\
\text { Management) }\end{array}$ & $\begin{array}{l}\text { Várias ferramentas da qualidade podem ser utilizadas para coleta e análise de } \\
\text { dados. As mais utilizadas são: diagrama de causa e efeito, gráficos de controle, } \\
\text { diagrama de afinidade, Diagrama Espinha de Peixe, Matriz Causa e Efeito, } \\
\text { Matriz Esforço x Impacto, Análise de Modo e Efeitos de Falha (FMEA), Mapa de } \\
\text { Processo etc. Tais ferramentas podem ser verificadas em Aguiar (2006), Pezeiro } \\
\text { (2005) e Campos (2004), dentre outros autores. }\end{array}$ & $x$ & $x$ \\
\hline Brainstorming & $\begin{array}{l}\text { Utilizado muito na maioria das fases de implementação do QRM, uma vez que } \\
\text { fornece possibilidades de melhoria e gera ideias. Essa técnica pode ser observada } \\
\text { com detalhes em Osborn (1963). }\end{array}$ & $x$ & $x$ \\
\hline $\begin{array}{l}\text { Ferramentas } \\
\text { estatísticas simples }\end{array}$ & $\begin{array}{l}\text { Cálculos de médias, moda, mediana, desvio padrão, histogramas, dentre outras } \\
\text { medidas e ferramentas estatísticas são fundamentais para o QRM, uma vez que } \\
\text { auxiliam na análise do processo estudado. Ferramentas estatísticas podem ser } \\
\text { encontradas em Bussab e Morettin (2002) e Walpole et al. (2009), dentre outros. }\end{array}$ & $x$ & $x$ \\
\hline $\begin{array}{l}\text { Dinâmica de Sistemas } \\
\text { (System Dynamics) }\end{array}$ & $\begin{array}{l}\text { Tem como foco principal a determinação da estrutura de um sistema, que por } \\
\text { sua vez, determina seu comportamento ao longo do tempo (FORRESTER, 1961). }\end{array}$ & $x$ & $\mathrm{x}$ \\
\hline $\begin{array}{l}\text { Benchmarking } \\
\text { interno }\end{array}$ & $\begin{array}{l}\text { O Benchmarking interno é utilizado para, dadas as características de um sistema } \\
\text { de operações estudado, avaliar se o lead time desse sistema está bom (próximo do } \\
\text { melhor desempenho possivel de um sistema qualquer - chamada região boa) ou } \\
\text { ruim (próximo do pior desempenho possível de um sistema qualquer - chamada } \\
\text { região ruim). Tanto o melhor quanto o pior desempenho possível (assim como } \\
\text { uma terceira situação,denominada situação prática) são calculados baseados na } \\
\text { chamada teoria de filas. Para detalhes ver Hopp e Spearman (2008). }\end{array}$ & $x$ & $x$ \\
\hline
\end{tabular}

Fonte: Elaborado pelos autores.

As propostas de melhorias para a redução do lead time são baseadas nos princípios e técnicas do QRM propostos por Suri (1998, 2010). 0 foco deste trabalho são as operações de escritório. Basicamente, Suri (1998) divide os princípios e ferramentas do QRM voltados ao escritório em três grandes grupos:

i. Princípios organizacionais (POE): os quais devem ser implementados impreterivelmente na sequência mostrada no Quadro 2.

ii. Princípios para manuseio e gestão da informação (PMGI): têm como objetivo dar suporte à implantação das células no escritório (Q-ROCs). Estes princípios são expostos no Quadro 3. iii. Princípios que exploram a dinâmica dos sistemas (system dynamics) para o escritório (PSD0): expandem a ideia de uma gestão científica no chão de fábrica para as operações de escritório. 0 Quadro 4 mostra esses princípios.

\section{Metodologia de pesquisa}

A pesquisa realizada neste trabalho utilizou os seguintes procedimentos: pesquisa teórico-conceitual (BERTO; NAKANO, 1998, 2000) e estudo de caso (YIN, 1994). A pesquisa teórico-conceitual, ou bibliográfica, foi realizada com o intuito de pré-orientação teórica 
Quadro 2. Princípios organizacionais.

\begin{tabular}{|c|c|}
\hline Princípio & Descrição \\
\hline POE 1: Focar um segmento do mercado & $\begin{array}{l}\text { Esse princípio é de suma importância, uma vez que o QRM não pode ser aplicado na } \\
\text { empresa como um todo de uma só vez. }\end{array}$ \\
\hline $\begin{array}{l}\text { POE 2: Determinar o produto do processamento } \\
\text { no escritório para este segmento }\end{array}$ & $\begin{array}{l}0 \text { produto se refere ao resultado dos passos realizados no escritório relativos ao segmento } \\
\text { de mercado escolhido no passo anterior. }\end{array}$ \\
\hline $\begin{array}{l}\text { POE 3: ldentificar as atividades no escritório } \\
\text { necessárias para se chegar a este produto }\end{array}$ & $\begin{array}{l}\text { Duas ferramentas são fundamentais para se identificar as atividades no escritório, a saber, } \\
\text { mapeamento do processo e tagging. }\end{array}$ \\
\hline $\begin{array}{l}\text { POE 4: Tentar subdividir o segmento estudado de } \\
\text { acordo com a simplicidade das atividades }\end{array}$ & $\begin{array}{l}\text { Este passo objetiva tentar identificar se existe algum subsegmento do mercado que } \\
\text { requer somente atividades mais simples, as quais poderiam ser separadas, fazendo com } \\
\text { que este segmento pudesse ser atendido em um tempo menor. }\end{array}$ \\
\hline $\begin{array}{l}\text { POE 5: Determinar se o subsegmento encontrado } \\
\text { no passo anterior representa uma } \\
\text { oportunidade de mercado significante }\end{array}$ & $\begin{array}{l}\text { Uma vez encontrado um segmento que pode ter seu lead time reduzido consideravelmente, } \\
\text { resta saber se existe uma parcela significativa do mercado interessada neste subsegmento. } \\
\text { Suri (1998) chama este subsegmento do mercado de FTMS (Focused target market } \\
\text { segment); caso exista vá para o passo seguinte (POE 6); caso contrário, retorne ao passo } \\
\text { anterior (POE 4). }\end{array}$ \\
\hline $\begin{array}{l}\text { POE 6: Focar os esforços i } \\
\text { niciais do QRM no FTMS }\end{array}$ & $\begin{array}{l}\text { Nesse passo deve ser demarcada a fronteira do FTMS, bem como devem ser identificados } \\
\text { os materiais, características, dentre outros itens a fim de que se possa focar o projeto } \\
\text { QRM neste segmento. }\end{array}$ \\
\hline $\begin{array}{l}\text { POE 7: Criar uma célula no } \\
\text { escritório para servir o FTMS }\end{array}$ & $\begin{array}{l}\text { A célula no escritório (Q-ROC) deve ser formada por pessoas multi-habilitadas responsáveis } \\
\text { por completar todas as atividades necessárias no escritório para o FTMS. }\end{array}$ \\
\hline $\begin{array}{l}\text { POE 8: Repensar o projeto das } \\
\text { operações para FTMS }\end{array}$ & $\begin{array}{l}\text { Dentro do Q-ROC, deve ser repensado como as operações poderiam ser reprojetadas } \\
\text { visando uma redução ainda maior de lead time. Exemplos de alterações nas atividades } \\
\text { que podem auxiliar na redução do lead time são: combinar passos, eliminar passos, } \\
\text { estabelecer fluxo contínuo, dentre outros. }\end{array}$ \\
\hline $\begin{array}{l}\text { POE 9: Fornecer recursos e suporte para } \\
\text { garantir o fluxo rápido dos trabalhos }\end{array}$ & $\begin{array}{l}\text { Muitas vezes serão necessários recursos adicionais para garantir o sucesso do Q-ROC, } \\
\text { como por exemplo, treinamento em múltiplas funções. }\end{array}$ \\
\hline $\begin{array}{l}\text { POE 10: Eliminar sistemas de } \\
\text { controle e de aprovação tradicionais }\end{array}$ & $\begin{array}{l}\text { Deve ser dada autonomia ao Q-ROC para tomar decisões, uma vez que os controles e } \\
\text { aprovações tradicionais levam ao aumento de passos necessários e consequente aumento } \\
\text { no lead time. }\end{array}$ \\
\hline $\begin{array}{l}\text { POE 11: Considerar a oportunidade de } \\
\text { integrar as células do escritório com } \\
\text { as células de manufatura }\end{array}$ & $\begin{array}{l}\text { Caso seja possivel, uma redução ainda maior no lead time é possível via integração do } \\
\text { Q-ROC com a célula de manufatura. }\end{array}$ \\
\hline
\end{tabular}

Fonte: Adaptado de Suri (1998).

Quadro 3. Princípios para manuseio e gestão da informação.

\begin{tabular}{|c|c|}
\hline Princípio & Descrição \\
\hline $\begin{array}{l}\text { PMG1 1: Implementar a regra } \\
\text { "no máximo uma" }\end{array}$ & $\begin{array}{l}\text { Esta regra defende que, após ser realizado o mapeamento do processo, deve-se eliminar fluxos } \\
\text { que façam com que uma tarefa passe duas ou mais vezes por uma pessoa ou departamento. }\end{array}$ \\
\hline $\begin{array}{l}\text { PMG1 2: Reexaminar se todas } \\
\text { as informações do produto } \\
\text { são realmente necessárias }\end{array}$ & $\begin{array}{l}\text { Reexaminar se todas as informações do produto são realmente necessárias: esse passo ajuda a } \\
\text { eliminar etapas e, com isso, lead time. }\end{array}$ \\
\hline $\begin{array}{l}\text { PMGl 3: Fornecer acesso } \\
\text { rápido e local à informação }\end{array}$ & $\begin{array}{l}\text { Fornecer acesso rápido e local à informação: o objetivo deste princípio é minimizar a dependência } \\
\text { do Q-ROC de informações externas. }\end{array}$ \\
\hline $\begin{array}{l}\text { PMGl 4: Tirar vantagem de } \\
\text { tecnologias de comércio eletrônico }\end{array}$ & $\begin{array}{l}\text { Tirar vantagem de tecnologias para a comércio eletrônico: tecnologias para facilitar a } \\
\text { comunicação devem ser utilizadas, como e-mail interno, ED1, Internet, banco de dados } \\
\text { compartilhados, arquivos em CAD, dentre outras. }\end{array}$ \\
\hline $\begin{array}{l}\text { PMG1 5: Investir em compatibilidade } \\
\text { de sistemas de informação }\end{array}$ & $\begin{array}{l}\text { Investir em compatibilidade de sistemas de informação: apesar de todo o esforço que se tem feito } \\
\text { neste sentido nos últimos anos, isto ainda não é uma realidade na maioria das empresas. }\end{array}$ \\
\hline
\end{tabular}

Fonte: Adaptado de Suri (1998).

a respeito do assunto QRM. O estudo de caso foi usado como forma de promover o entendimento da situação de uma empresa fabricante de materiais de escrita (lápis de cor e grafite, canetas, lapiseiras etc.) que possui alto lead time na realização das tarefas do processo de orçamentação e, então, propor a aplicação da abordagem QRM. Essa empresa foi selecionada por amostragem não probabilística e intencional (PATTON, 1990). Foram analisadas todas as atividades das quatro áreas que participam do processo de orçamentação na empresa: i) comercial; ii) planejamento da produção; iii) orçamento e custos; iv) diretoria. As principais fontes de dados para a realização deste trabalho foram: entrevista com a chefia, estudo dos tempos das atividades e dados do sistema ERP (Enterprise Resource Planning) da empresa. Ressalta-se que todas essas fontes de dados foram utilizadas em todas as etapas da pesquisa.

As etapas do estudo realizado seguiram a metodologia proposta pela abordagem QRM. Essas etapas e ferramentas utilizadas em cada uma delas são apresentadas na Figura 1. Como pode ser visto, os princípios e técnicas 
Quadro 4. Princípios que exploram a dinâmica dos sistemas para o escritório.

\begin{tabular}{|c|c|}
\hline Princípio & Descrição \\
\hline $\begin{array}{l}\text { PSDE 1: Planejar estrategicamente } \\
\text { para ter capacidade ociosa }\end{array}$ & Como visto anteriormente, $100 \%$ de utilização prejudica o lead time. \\
\hline $\begin{array}{l}\text { PSDE 2: Substituir as } \\
\text { medidas tradicionais de } \\
\text { eficiência no escritório }\end{array}$ & $\begin{array}{l}\text { Assim como no chão de fábrica, a medida de desempenho fundamental deve ser a redução de lead } \\
\text { time. }\end{array}$ \\
\hline PSDE 3: Reduzir a variabilidade & $\begin{array}{l}\text { De acordo com a teoria de filas, a variabilidade (tanto no input quanto no tempo de processamento) } \\
\text { é prejudicial ao lead time. Algumas técnicas para a redução da variabilidade no escritório são: } \\
\text { padronização de procedimentos, padronização de roteiros, eliminação de retrabalhos, separação de } \\
\text { atividades simples e complexas, dentre outras. }\end{array}$ \\
\hline $\begin{array}{l}\text { PSDE 4: Utilizar junção de } \\
\text { recursos e filas únicas }\end{array}$ & $\begin{array}{l}\text { Ambas as medidas reduzem o lead time, porém existem pré-requisitos que devem ser atendidos para } \\
\text { que estas medidas sejam implementadas; tais como: os recursos precisam ser flexíveis para servir as filas } \\
\text { únicas e as tarefas devem ser projetadas para permitir a flexibilidade. }\end{array}$ \\
\hline $\begin{array}{l}\text { PSDE 5: Transformar as } \\
\text { atividades sequenciais em paralelo }\end{array}$ & Esta medida pode ter impacto importante na redução do lead time. \\
\hline $\begin{array}{l}\text { PSDE 6: Reduzir os tempos de } \\
\text { setup e os tamanhos de lotes }\end{array}$ & $\begin{array}{l}\text { Assim como no chão de fábrica, deve haver um esforço para a redução de setup e tamanho de lotes nas } \\
\text { operações de escritório, uma vez que ambos têm impacto negativo no lead time. }\end{array}$ \\
\hline $\begin{array}{l}\text { PSDE 7: Utilizar gestão de } \\
\text { capacidade e controle de input }\end{array}$ & $\begin{array}{l}\text { Deve-se calcular e analisar periodicamente a capacidade dos Q-ROCs. Não se deve liberar tarefas sem } \\
\text { que haja capacidade disponível. Esta análise de capacidade pode ser feita de várias formas: simples } \\
\text { aplicação da lei de Little, planilhas, softwares de simulação ou softwares de modelagem rápida } \\
\text { (RMP - Rapid Modeling Technique). Para controlar o input de tarefa, o sistema POLCA pode também } \\
\text { ser utilizado no escritório. }\end{array}$ \\
\hline $\begin{array}{l}\text { PSDE 8: Criar uma } \\
\text { organização flexivel }\end{array}$ & $\begin{array}{l}\text { Criar uma organização flexível: várias medidas contribuem neste sentido; por exemplo, deve haver } \\
\text { certa flexibilidade entre as células (tarefas podem ser processadas em mais de uma célula), pode-se } \\
\text { utilizar trabalhadores flutuantes (trabalhadores que servem várias células), ou mesmo migrações entre } \\
\text { as células em períodos de sazonalidade, dentre outras medidas. }\end{array}$ \\
\hline
\end{tabular}

Fonte: Adaptado de Suri (1998).

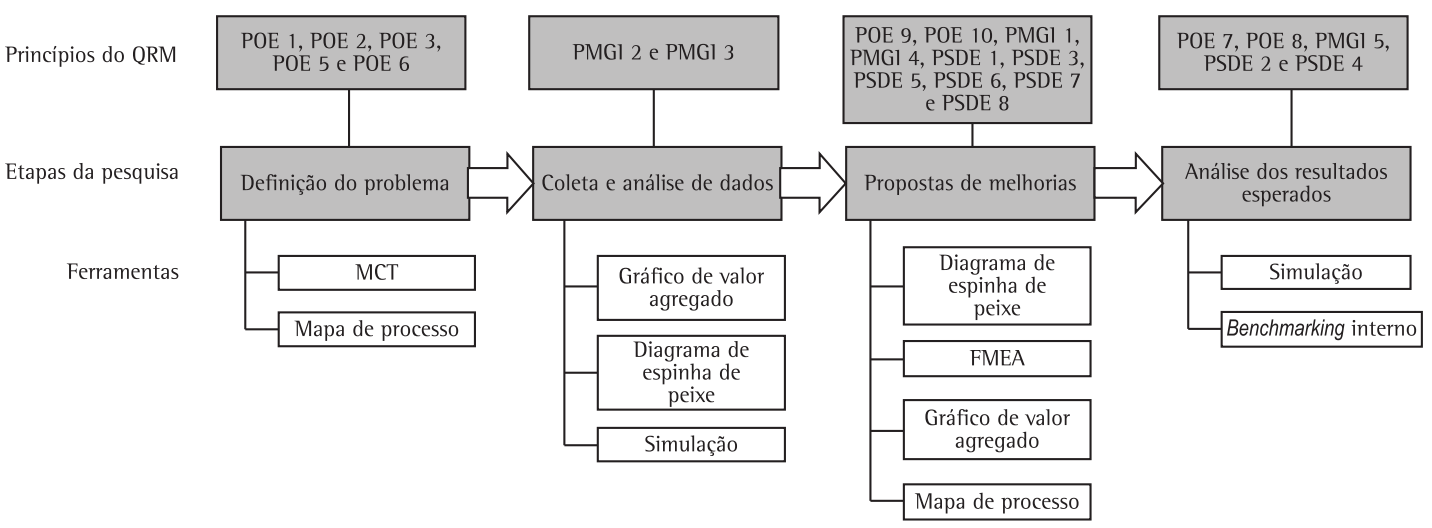

Figura 1.Etapas da pesquisa, ferramentas e princípios do QRM utilizados. Fonte: Elaborado pelos autores.

do QRM nortearam as etapas de coleta e análise de dados, propostas de melhorias e análise dos resultados esperados. A discussão sobre o uso dos princípios e técnicas do QRM, do uso das ferramentas e das etapas da pesquisa é realizada nas seções posteriores.

Cabe ressaltar que, para a utilização das ferramentas nas etapas da pesquisa, foram seguidas as recomendações de: i) Suri (1998), para o MCT e o Gráfico de Valor Agregado; ii) Pezeiro (2005), para o Mapa de Processo, o Diagrama de Espinha de Peixe, e a FMEA; iii) Law e Kelton (1991), para a simulação; e iv) Hopp e Spearman (2008), para o Benchmarking Interno. Segundo a abordagem QRM, o uso do MCT é obrigatório. As demais ferramentas foram selecionadas mediante a verificação da possibilidade de uso na realidade das operações de escritório da empresa e devido a suas características apresentadas pelos referidos autores. Além disso, também se considerou a adequação dessas ferramentas para cada etapa da pesquisa.

A relação das ferramentas utilizadas e a ordem lógica de uso destas nas etapas do trabalho são expostas no Quadro 5.

\section{0 estudo de caso}

Nessa seção, são expostas algumas informações sobre a empresa estudada e sobre o processo 
Quadro 5. Relação de ferramentas utilizadas e sua ordem lógica dentro das etapas do trabalho.

\begin{tabular}{|c|c|c|c|c|}
\hline Fase & Etapa & Atividade & Ferramenta & Pergunta-chave \\
\hline 1 & $\begin{array}{l}\text { Definição do } \\
\text { Problema }\end{array}$ & $\begin{array}{l}\text { Analisar a situação atual para identificar } \\
\text { e compreender os problemas existentes }\end{array}$ & MCT; Mapa de Processo & $\begin{array}{l}0 \text { que é e por que o processo } \\
\text { estudado é importante? }\end{array}$ \\
\hline 2 & $\begin{array}{l}\text { Coleta e Análise } \\
\text { de Dados }\end{array}$ & $\begin{array}{c}\text { Analisar os dados coletados; separar fatos } \\
\text { relevantes de versões de baixa relevância; } \\
\text { identificar as causas }\end{array}$ & $\begin{array}{l}\text { Gráfico de Valor Agregado; } \\
\text { Diagrama de Espinha de Peixe; } \\
\text { Simulação }\end{array}$ & $\begin{array}{l}\text { Quais são as entradas e } \\
\text { saídas do processo? }\end{array}$ \\
\hline 3 & $\begin{array}{l}\text { Propostas de } \\
\text { Melhorias }\end{array}$ & $\begin{array}{l}\text { Encontrar as soluções } \\
\text { potenciais para o problema }\end{array}$ & $\begin{array}{c}\text { FMEA; Diagrama Espinha de Peixe; } \\
\text { Gráfico de Valor Agregado; Mapa } \\
\text { de Processo }\end{array}$ & $\begin{array}{l}\text { Quais as ações tomadas } \\
\text { para melhorar o processo? }\end{array}$ \\
\hline 4 & $\begin{array}{c}\text { Análise dos } \\
\text { Resultados Esperados }\end{array}$ & $\begin{array}{c}\text { Implementar as ações } \\
\text { potenciais de melhoria e } \\
\text { levantar o que mudou no processo }\end{array}$ & Simulação; Benchmarking Interno & $\begin{array}{l}\text { As ações tomadas } \\
\text { melhoraram o processo? }\end{array}$ \\
\hline
\end{tabular}

Fonte: Elaborado pelos autores.

de orçamentação. Ademais, são apresentadas as ferramentas utilizadas nas etapas de definição do problema, na coleta e análise de dados e nas propostas de melhorias, e, também, a análise dos resultados esperados.

\subsection{A empresa estudada e o processo de orçamentação}

A empresa estudada, fabricante de materiais de escrita, constitui-se numa empresa de grande porte (multinacional) do tipo sociedade anônima. Atualmente, emprega cerca de 2.500 funcionários no País.

0 processo de orçamentação da empresa pesquisada tem como objetivo a elaboração do resultado/desempenho previsto para o próximo ano fiscal. Esse processo exerce um papel ativo na empresa estudada, funcionando como um centro de informações da empresa e requer, processa e fornece informações para muitos outros departamentos da organização. Nesse processo, a formação dos custos é fortemente revisada, assim como as despesas e vendas esperadas para o próximo período fiscal. É por meio deste orçamento prévio que a diretoria da empresa se compromete com seus investidores em relação ao desempenho do período, tanto em termos de lucratividade como também em gestão de capital. Consequentemente, durante o processo de orçamentação há uma participação direta da alta gerência/diretoria a fim de analisar as oportunidades de negócio para o período, as estratégias de mercado, as estratégias de manufatura e compras e os investimentos, uma vez que todos exercem papel na determinação dos custos e rentabilidades para o período.

A orçamentação se inicia com o levantamento dos volumes de faturamento por item (SKU - Stock Keeping Unit) pela área comercial. Logo após, a área de Planejamento da Produção recebe essas informações e realiza o plano mestre de produção por item. Esse plano é analisado ainda nessa área em conjunto com gestores e gerências, buscando gargalos e possibilidade de alteração do planejamento da produção. Caso o plano não seja aprovado, retorna para a área comercial. Se aprovado, segue para a área de orçamento e custos. Nessa área há o cálculo das horas necessárias para a produção dos itens com base nos roteiros produtivos. Há, também, o cálculo dos gastos com base na estrutura técnica de matéria-prima utilizada na produção dos itens assim como dos gastos das utilidades (água, luz, depreciação do maquinário etc.) e dos gastos com mão de obra. Com isso, é possível o cálculo das tarifas (custo hora planejado) para o custeio dos produtos. Logo após, essas informações seguem para a diretoria para aprovação ou não do orçamento. Caso não seja aprovado, este retorna para a área de orçamento e custos para devidos acertos. As etapas do processo encontram-se listadas no Quadro 6.

Cabe ressaltar que o sistema de custeio adotado nessa empresa é o custeio por absorção. Padoveze (2007) define o custeio por absorção como o método tradicional de custeamento, no qual, para se obter o custo de um produto, consideram-se todos os gastos industriais, diretos ou indiretos, fixos ou variáveis, sendo que os gastos indiretos são alocados aos produtos por critérios de rateio. A modelagem de um sistema de custeio por absorção pode ser encontrada em Martins (2006).

A Figura 2 explicita a distribuição da mão de obra e o fluxo de informações entre as áreas da empresa envolvidas no processo de orçamentação. Como pode ser observado, nos setores comercial e de planejamento da produção há duas pessoas em cada área dedicadas à realização de suas atividades. Entre essas áreas, há troca constante de informações. No setor de orçamentos e custos, há a alocação de três pessoas, sendo que essa área recebe informações do setor de planejamento da produção para execução de suas atividades. A diretoria é composta por dois diretores, os quais recebem e enviam informações de e para o setor de orçamentos e custos. 
Quadro 6. Descrição das etapas do processo de orçamentação da empresa.

\begin{tabular}{|c|c|}
\hline Etapa & Descrição etapa \\
\hline A & Levantar o volume de faturamento por item \\
\hline B & Rodar o Plano Mestre de Produção por item \\
\hline C & $\begin{array}{l}\text { Realizar uma análise da capacidade produtiva } \\
\text { (viabilidade do plano) }\end{array}$ \\
\hline D & $\begin{array}{c}\text { Extrair as estruturas operacionais dos produtos } \\
\text { (horas homem e máquina) }\end{array}$ \\
\hline E & $\begin{array}{l}\text { Calcular a necessidade de recursos produtivos } \\
\text { (mão de obra e máquina) }\end{array}$ \\
\hline $\mathrm{F}$ & Levantar consumo previsto com Energia+Água+Esgoto \\
\hline G & Levantar base de rateio prevista \\
\hline $\mathrm{H}$ & Dimensionar necessidades de manutanção interna \\
\hline 1 & Dimensionar gastos com pessoal (MOD/MOl) \\
\hline $\mathrm{J}$ & Levantar depreciação prevista \\
\hline $\mathrm{L}$ & Levantar gastos previstos com compra de matéria-prima \\
\hline $\mathrm{M}$ & Levantar a apropriação de projetos de redução de custos \\
\hline $\mathrm{N}$ & Calcular as tarifas de mão-de-obra e máquina previstas \\
\hline 0 & Reposicionar o custo dos produtos vendidos \\
\hline $\mathrm{P}$ & Avaliar cenário econômico-financeiro junto à Diretoria \\
\hline Q & $\begin{array}{l}\text { Realizar a carga dos dados no sistema e } \\
\text { gravar os custos planejados }\end{array}$ \\
\hline
\end{tabular}

Fonte: Elaborado pelos autores.

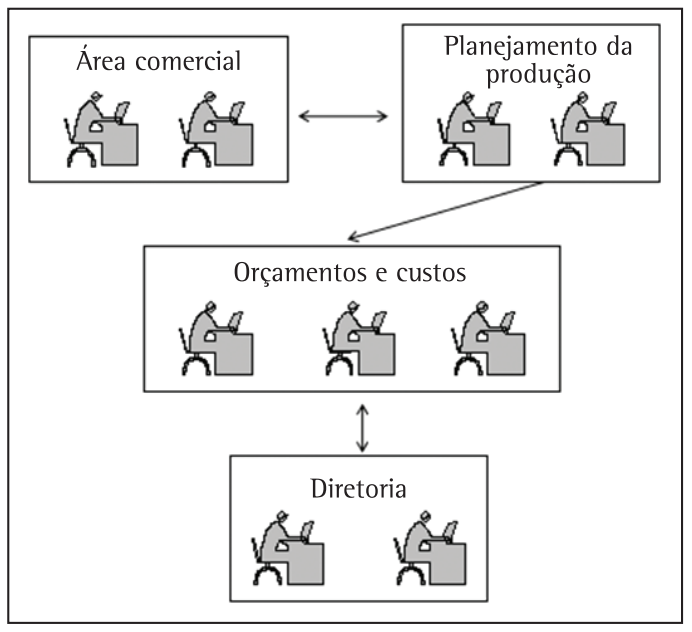

Figura 2. Layout atual. Fonte: Elaborado pelos autores.

\subsection{Definição do problema}

Nessa seção, há a exposição das ferramentas utilizadas na etapa de definição do problema. Para tanto, foram utilizadas as ferramentas MCT (Manufacturing Critical-path Time) e Mapa de Processo.

\subsection{1. $M C T$}

0 MCT mostra a quantidade de tempo efetivamente produtivo incorporado ao produto/atividade. Para que fosse possivel a elaboração do MCT, realizou-se a coleta de informações junto aos vários atores envolvidos no processo de orçamentação da empresa. Com isso, tornou-se possível o entendimento da estrutura do processo e as decisões envolvidas em cada etapa deste processo.

A Figura 3 ilustra o MCT para o processo de orçamentação da empresa em questão. O MCT representado nesta figura foi obtido a partir da análise de dados passados a respeito da operação orçamentação. A descrição das etapas foi exposta no Quadro 6. Vale ressaltar que a barra em cinza da Figura 3 representa a quantidade de tempo da etapa em que há agregação de valor. Já a barra em preto representa a quantidade de tempo da etapa em que não há agregação de valor. Exemplos de atividades nessa categoria estão esperas, retrabalhos, tempo excessivo para realização da etapa, entre outros.

Portanto, com a elaboração do MCT, obtiveram-se informações de como o trabalho é realizado e estabeleceu-se uma estimativa inicial de como se comporta o lead time entre os vários estágios do processo. Verificou-se que o tempo total gasto para a realização do processo de orçamentação é de aproximadamente dois meses e meio (aproximadamente 76 dias), sendo que 60,3\% desse tempo gasto não agrega valor ao processo. Além disso, observou-se que a etapa $\mathrm{N}$ (cálculo das tarifas de mão de obra e máquina previstas) é a atividade que mais contribui para o aumento do tempo de não agregação de valor.

\subsubsection{Mapa de processo}

Com essa ferramenta, foi realizada a ilustração gráfica do processo de orçamentação da empresa estudada com o objetivo de identificar todas as atividades específicas que ocorrem ao longo do fluxo de valor. Destaca-se que o mapa de processo pode referir-se a um produto ou serviço.

A Figura 4 expõe o mapa de processo elaborado a partir da análise das dependências entre as etapas do processo, análise esta feita com auxílio de um especialista do processo de orçamentação da empresa estudada. Como pode ser visto, a etapa ' $C$ ' (realizar uma análise da capacidade produtiva), que é um ponto de verificação, precede a etapa ' $D$ ' (extrair as estruturas operacionais dos produtos), sendo que há um ponto de decisão entre essas etapas. Se a análise da capacidade produtiva está correta, as estruturas operacionais dos produtos são extraídas. Caso contrário, retorna-se para a etapa 'B' (rodar o plano mestre de produção por item). Na etapa 'D', as principais saídas do processo que interferem na atividade, sob a ótica do cliente, são o lead time do processo de orçamentação 


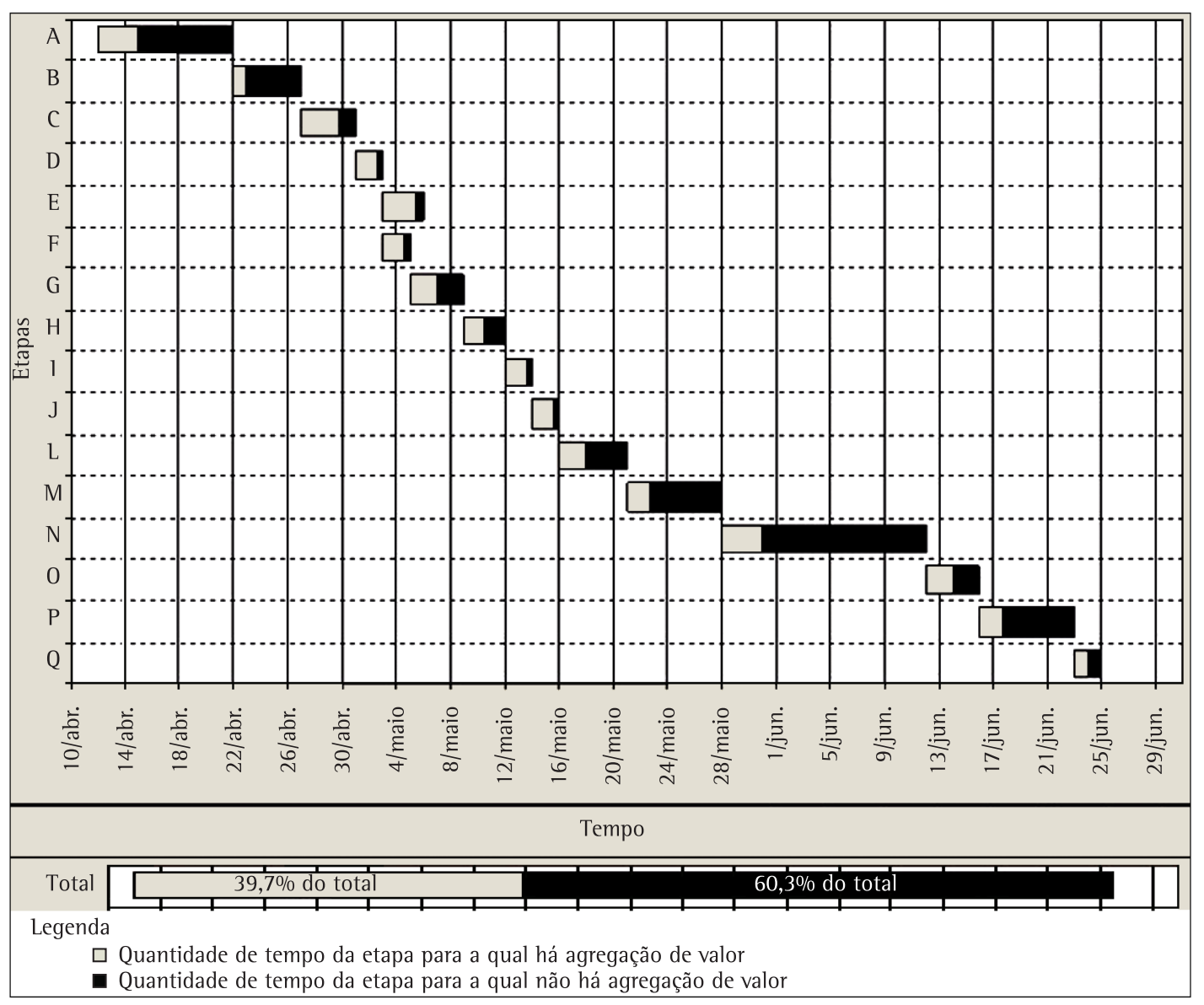

Figura 3. MCT das fases da orçamentação. Fonte: Elaborado pelos autores.

e a confiabilidade nos resultados do processo de orçamentação. Nota-se, também, que as atividades destacadas em cinza constituem o caminho crítico do processo de orçamentação.

Comparando-se o MCT (como de fato o processo é realizado) com o mapa de processo (como o processo poderia ser realizado) foi possível constatar que há diferenças entre ambos. A principal diferença é que as atividades são apresentadas no MCT de modo sequencial e, no Mapa de Processos, estas atividades podem ser mais bem executadas em paralelo. Por exemplo, as atividades 'Calcular a Necessidade de Recursos Produtivos', 'Calcular o Consumo Previsto com Energia + Água + Esgoto' e 'Levantar Gastos Previstos com Compra de Matéria-Prima', que no MCT são sequenciais, podem ser organizadas de modo paralelo no Mapa de Processo. Isso é devido ao fato de que o MCT mostra a situação atual do processo, enquanto que o mapa do processo já mostra algumas possibilidades de melhorias, ilustrando, portanto, algo mais próximo de uma situação ideal, situação essa, porém, factível, de acordo com os especialistas da empresa.

\subsection{Coleta e análise de dados}

Nesta seção, são expostas e discutidas as ferramentas utilizadas para coleta e análise de dados, a saber: gráfico de valor agregado, diagrama de espinha de peixe e simulação.

\subsubsection{Gráfico de valor agregado}

0 gráfico de valor agregado, ilustrado na Figura 5, demonstra como se dá a integralização do processo a partir da visualização do seu valor agregado no tempo.

A partir da análise do gráfico de valor agregado observa-se que, para as 8 primeiras etapas (etapas de A até $H$ ) do processo de orçamentação, demora-se $44 \%$ do tempo para agregar apenas $22 \%$ de valor, ou seja, se gasta muito tempo para avançar o processo. 


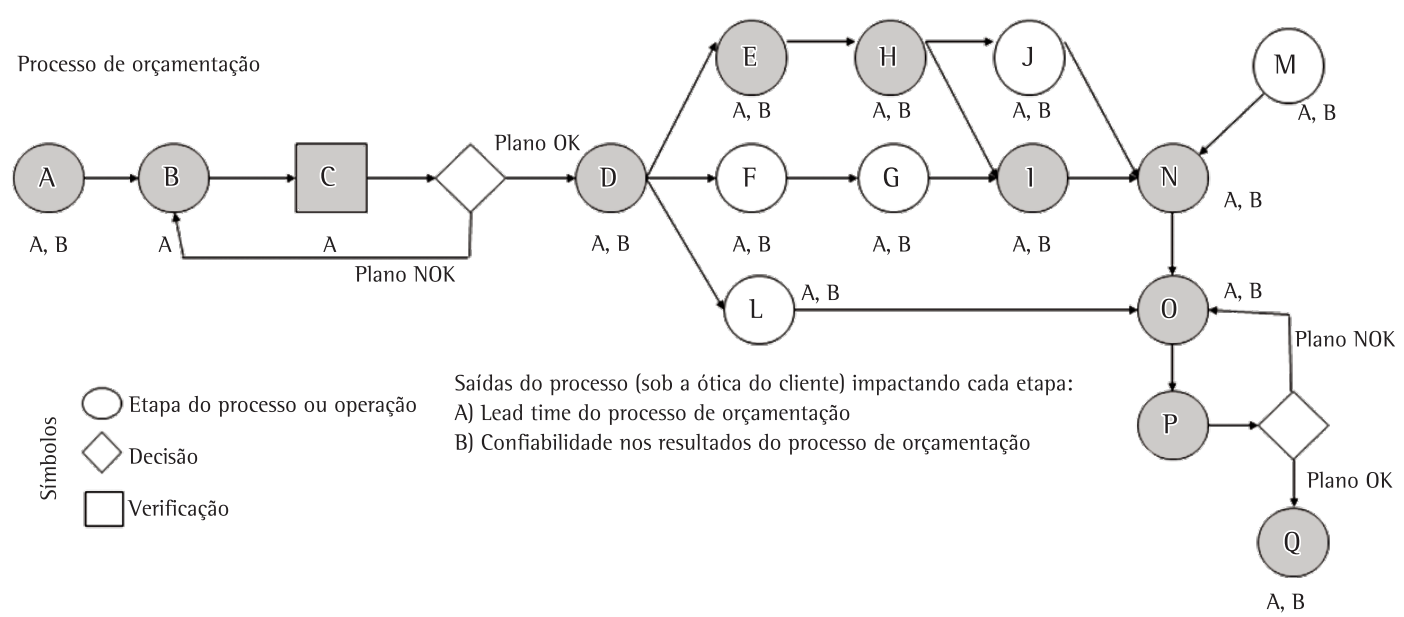

Figura 4. 0 mapa do processo de orçamentação. Fonte: Elaborado pelos autores.

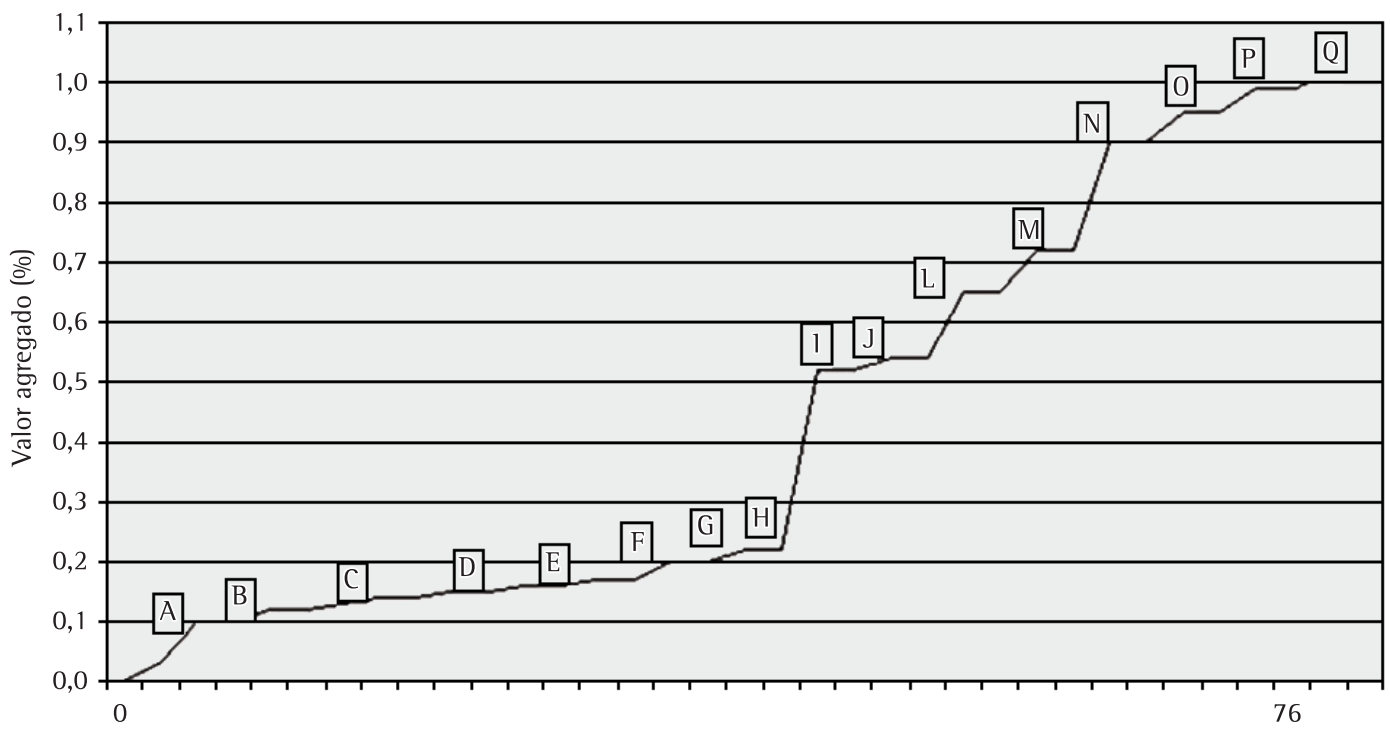

Dias

Figura 5. Gráfico de valor agregado. Fonte: Elaborado pelos autores.

\subsubsection{Diagrama espinha de peixe}

0 diagrama espinha de peixe foi utilizado para apresentar a relação existente entre o problema analisado (alto lead time) e suas possíveis causas. 0 diagrama obtido para o processo de orçamentação pode ser visto na Figura 6.

Na Figura 6, nota-se que existem 20 causas levantadas para o problema de alto lead time do processo de orçamentação. Essas causas se encontram distribuídas em seis categorias, a saber: i) meio de medida: 'x1', ‘x2', 'x3' e 'x12'; ii) material: 'x18'e 'x20'; iii) mão de obra: 'x7', 'x17', 'x14' e 'x11'; iv) meio ambiente: ' $x 4$ ' e ' $x 9$ '; v) método: ' $x 8$ ', ' $x 10$ ', 'x13', 'x15', 'x16' e 'x19'; vi) máquina: 'x5' e 'x6'. Assim, por exemplo, na categoria 'método' dentre as causas encontradas para o alto lead time estão a sobreposição de atividades e a falta de procedimento detalhado para execução.

\subsubsection{Simulação}

Foi realizada, no software Arena ${ }^{\circledR}$, a simulação computacional do cenário atual do processo de orçamentação com intuito de obter um cenário base confiável para gerar o cenário contendo as melhorias 


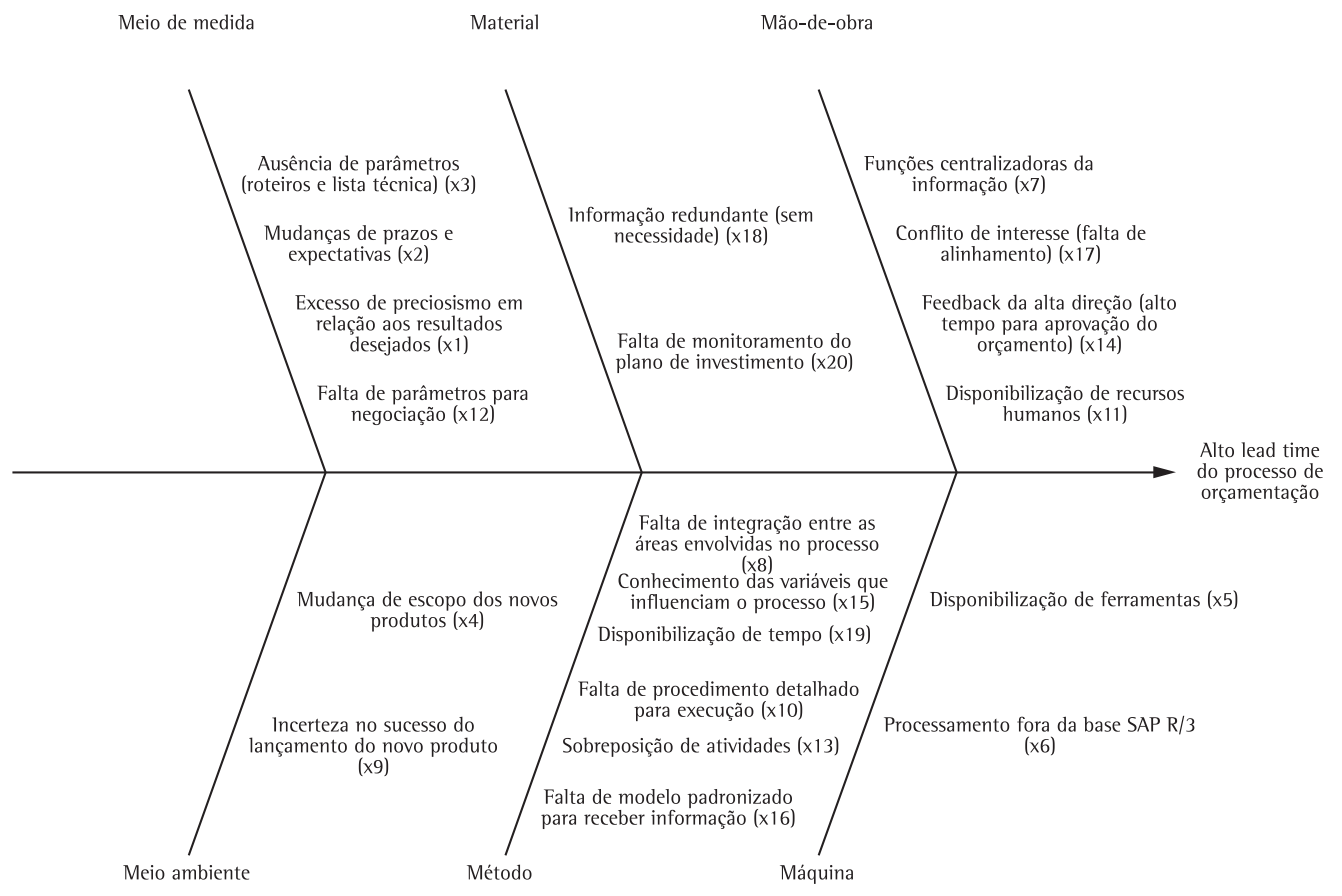

Figura 6. Diagrama Espinha de Peixe observado para a orçamentação. Fonte: Elaborado pelos autores.

propostas. Além disso, a simulação computacional permitiu considerar no modelo a aleatoriedade envolvida no processo. Tal ponto não pôde ser considerado nas ferramentas MCT e Gráfico de Valor Agregado para obtenção do lead time total do processo, devido às relações determinísticas embutidas nessas ferramentas.

Para a condução da simulação, foi utilizada a metodologia proposta por Law e Kelton (1991), que consiste nas seguintes etapas: formulação do problema e planejamento do estudo; coleta dos dados e definição do modelo; validação (dados de entrada); construção do programa e verificação; realização das rodadas-piloto de simulação; validação (modelo); planejamento dos experimentos; execução das simulações; análise dos resultados; documentação, apresentação e implementação dos resultados.

Os principais dados coletados por meio da simulação do cenário atual foram: i) tempo de agregação de valor: 29,1 dias; ii) tempo de não agregação de valor: 49,3 dias; iii) lead time total: 78,4 dias. Esses valores são bem próximos aos encontrados pelo MCT.

\subsection{Propostas de melhorias}

Conforme informado na seção 3, algumas ferramentas foram utilizadas com diversos propósitos. Nessa etapa da pesquisa, foram utilizadas as ferramentas: diagrama de espinha de peixe (subseção 4.3.2), gráfico de valor agregado (subseção 4.3.1) e mapa de processo (subseção 4.3.2). Também nessa etapa da pesquisa, foi utilizada a ferramenta FMEA, a qual auxiliou na proposição de quatro propostas de melhorias.

Ressalta-se que a condução da FMEA foi realizada com base em Pezeiro (2005) e juntamente com a chefia e com os funcionários da empresa envolvidos diretamente com a orçamentação. No processo analisado, essa ferramenta gerencial identificou as maneiras pelas quais este pode falhar, ajudando, também, na identificação de ações que evitem que esses problemas ocorram.

Dessa forma, a elaboração da FMEA se deu a partir de uma análise crítica de quais eram as principais etapas do processo de orçamentação que tinham variáveis de entrada (potencial X) que, de alguma forma, poderiam falhar em cumprir com sua função, aumentando, assim, o lead time do processo analisado. As etapas que se enquadram nesse contexto são: i) aprovação da diretoria; ii) determinação da base de rateio; iii) elaboração do custo de produção; e iv) levantamento da depreciação prevista. Cabe salientar que essas etapas são formadas e/ou influenciadas por algumas fases do processo de orçamentação, por exemplo, dentre as fases componentes da etapa de elaboração do custo de produção estão 'levantar gastos previstos com compra de matéria-prima', 'calcular as tarifas de mão de obra e máquina previstas' e 'calcular a necessidade de recursos produtivos (mão de obra e máquina)'.

A priorização das medidas de contenção foi baseada no cálculo do Número de Prioridade de 
Risco (RPN). Quanto maior o valor do RPN, maior será o risco da potencial falha do processo. 0 RPN foi calculado pela multiplicação dos seguintes fatores:

Severidade do efeito ('S'): foram atribuídos graus de 1 a 10 , sendo que 1 significa que o efeito do modo de falha tem baixa severidade e 10 indica que o efeito do modo de falha é bastante severo;

Probabilidade de ocorrência de causa do modo de falha ('0'): foram atribuídos graus de 1 a 10.0 valor 1 denota que a probabilidade de ocorrer a causa do modo de falha é praticamente nula e 10 significa que a probabilidade de ocorrer a causa do modo de falha é em torno de 100\%;

Probabilidade de detecção da causa do modo de falha com o controle atual existente ('D'): valor de 1 a 10 , em que 1 significa que, com o controle atual existente, é de praticamente 100\% a probabilidade de se encontrar a causa do modo de falha, enquanto 10 significa que não há controle nenhum ou o controle existente tem uma probabilidade praticamente nula de detectar a causa do modo de falha.

A FMEA realizada é apresentada no Quadro 7. Como pode ser observado, na etapa de determinação da base de rateio, as variáveis de entrada são os critérios para sua elaboração. 0 potencial modo de falha é o critério estabelecido não ter relação com o centro de custo, e o efeito é a desconsideração das decisões/ especificações acordadas para o uso dos critérios na elaboração da base de rateio. Verificou-se que as causas dessa falha são a falta de monitoramento na definição dos critérios e que os responsáveis pela orçamentação aceitam solicitação de mudança no critério sem questionar a integridade da informação. Além disso, não há um controle estabelecido para evitar tais problemas. Assim, possíveis ações de melhoria identificadas foram a criação de procedimento para levantar os critérios com as áreas, e ter uma base histórica dos critérios adotados em meses anteriores.

Assim, a partir da FMEA aplicada, originaram-se quatro ações com impacto na redução de lead time do processo de orçamentação, a saber:

- Criar procedimento para o levantamento dos critérios para determinação da base de rateio com as áreas envolvidas na orçamentação. Aqui, cabe ter uma base histórica dos critérios adotados em meses anteriores;

- Realizar o acompanhamento do projeto de investimento ao longo do tempo e dos componentes que foram agregados ao longo da vida de uma máquina, por exemplo, no levantamento da depreciação prevista;

- Planejar o projeto do produto formalmente, exigindo-se o cumprimento das tarefas. Nessa melhoria, cabe utilizar os diários de bordo na determinação dos tempos operacionais;

- Criar um check-list para validar as etapas anteriores à aprovação da diretoria com as áreas envolvidas. Assim, é necessário obter formalmente o comprometimento das áreas com o processo de orçamentação.

Algumas modificações, que poderiam reduzir o lead time do processo de orçamentação, foram sugeridas com base nas análises efetuadas por meio das ferramentas empregadas neste estudo. 0 Quadro 8 expõe quais foram as modificações propostas, as etapas do processo de orçamentação afetadas, a ferramenta de análise utilizada, a qual permitiu a visualização de um problema (atacado pela modificação proposta), as causas do alto lead time impactadas pela modificação proposta e os ganhos estimados em função das modificações propostas. A primeira coluna do Quadro 8 contém o número da subseção que possui maiores detalhes sobre a modificação proposta (título da subseção).

\subsubsection{Diminuição do tempo gasto em atividades que não agregam valor}

Conforme analisado por meio do gráfico de valor agregado (subseção 4.3.1), as oito primeiras etapas do processo de orçamentação (etapas de 'A' até ' $H$ ') requerem $44 \%$ do tempo para agregar apenas $22 \%$ de valor (se gasta muito tempo para avançar o processo). As atividades de não agregação de valor destas etapas envolvem a verificação de eventuais erros, a verificação da integridade dos dados, a comparação com dados de anos anteriores e espera de checagem final da chefia. Estas atividades que não agregam valor muitas vezes são consideradas necessárias. Estudando-se um pouco mais a fundo essas atividades, estabeleceu-se que é possível reduzir em 20\% o tempo gasto com atividades que não agregam valor nessas primeiras atividades somente com:

- Um melhor planejamento de informações e ferramentas a serem utilizadas no processo: com isso minimiza-se a utilização de ferramentas fora do sistema ERP;

- Maior definição de objetivos: nesses estágios iniciais não há necessidade de tanto detalhamento nos dados; e

- Maior delegação de atividades.

Dessa forma, implementando-se essas melhorias, tem-se um efeito direto nas seguintes causas do lead time longo (identificadas na Figura 6): i) excesso de preciosismo em relação aos resultados desejados (x1); ii) disponibilização de ferramentas (x5); iii) processamento fora da base SAP R/3 (x6); iv) feedback da alta direção (alto tempo para aprovação do orçamento - x14); v) informação redundante (sem necessidade $-\mathrm{x} 18$ ).

\subsubsection{Desconsiderar o impacto da mudança de escopo de novos produtos no orçamento}

Foi levantada, a partir do diagrama de espinha de peixe, que uma causa do alto lead time é a mudança 
Quadro 7. FMEA desenvolvida.

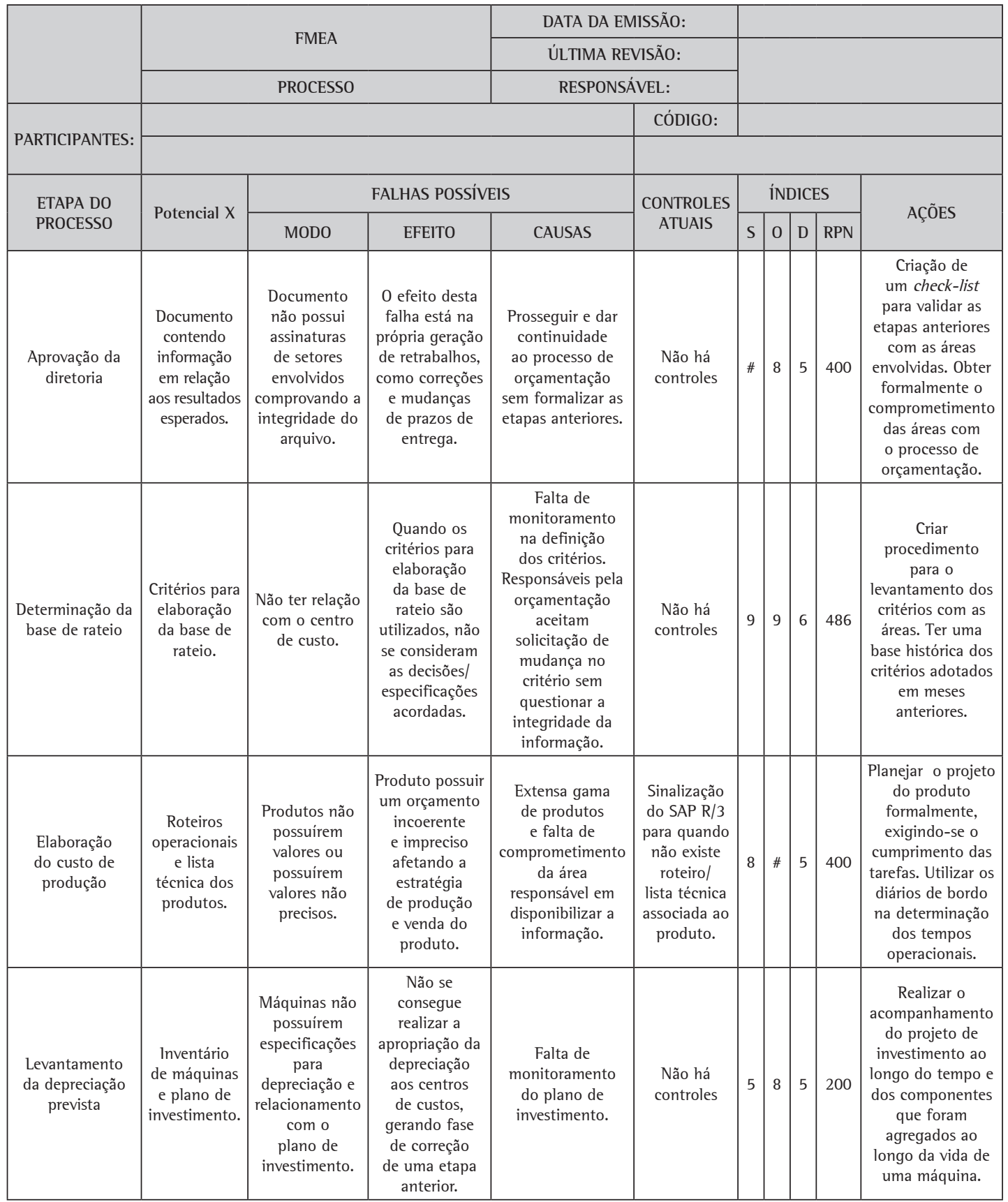

Fonte: Elaborado pelos autores.

de escopo de novos produtos (x4) e a incerteza do sucesso de um novo produto (x9). Durante a análise dos dados históricos da empresa foi possível constatar que o lançamento de novos produtos não traz grandes impactos no faturamento da empresa, pois eles estão em uma faixa de faturamento muito pequena ( $R \$ 0$ a $R \$ 5.000)$. Sendo assim, propõe-se aqui que, caso haja mudança de escopo de um novo produto, tal mudança deve ser desprezada para efeitos de orçamentação, pois tal produto não irá contribuir de maneira considerável na acuracidade do processo. Estimou-se uma redução de 5\% nos tempos de agregação de valor e de não agregação de valor como consequência dessa recomendação proposta em virtude do fato de que os registros históricos 
Quadro 8. Resumo das modificações propostas.

\begin{tabular}{|c|c|c|c|c|c|c|c|}
\hline \multirow[b]{2}{*}{ Subseção } & \multirow[b]{2}{*}{$\begin{array}{l}\text { Modificação proposta } \\
\text { (o que fazer?) }\end{array}$} & \multirow[b]{2}{*}{$\begin{array}{c}\text { Quais } \\
\text { etapas serão } \\
\text { afetadas } \\
\text { (onde fará?) }\end{array}$} & \multirow[b]{2}{*}{$\begin{array}{l}\text { Ferramenta } \\
\text { de análise } \\
\text { utilizada }\end{array}$} & \multirow[b]{2}{*}{$\begin{array}{l}\text { Causas do alto } \\
\text { impactadas pela } \\
\text { modificação } \\
\text { proposta }\end{array}$} & \multicolumn{3}{|c|}{ Haverá ganhos com a proposta? Qual? } \\
\hline & & & & & $\begin{array}{l}\text { Redução } \\
\text { do tempo } \\
\text { de não } \\
\text { agregação } \\
\text { de valor }\end{array}$ & $\begin{array}{l}\text { Redução do } \\
\text { tempo de } \\
\text { agregação } \\
\text { de valor }\end{array}$ & Outros ganhos \\
\hline 4.4 .1 & $\begin{array}{c}\text { Diminuir o tempo gasto } \\
\text { em atividades que não } \\
\text { agregam valor }\end{array}$ & $\begin{array}{l}\text { B, D, E, } \\
F, \text { G, H }\end{array}$ & $\begin{array}{l}\text { Gráfico } \\
\text { de valor } \\
\text { agregado }\end{array}$ & $\begin{array}{c}x 1, x 5, x 6 \\
\times 14, \times 18\end{array}$ & $20 \%$ & Não & Não \\
\hline 4.4 .2 & $\begin{array}{c}\text { Não levar em consideração } \\
\text { o impacto da mudança de } \\
\text { escopo de novos produtos } \\
\text { no orçamento }\end{array}$ & Todas & $\begin{array}{l}\text { Diagrama } \\
\text { de espinha } \\
\text { de peixe }\end{array}$ & $x 4, x 9$ & $5 \%$ & $5 \%$ & Não \\
\hline 4.4 .3 & $\begin{array}{l}\text { Criar procedimentos } \\
\text { para o levantamento dos } \\
\text { critérios de rateio com } \\
\text { as áreas envolvidas na } \\
\text { orçamentação }\end{array}$ & G & FMEA & $x 8, x 10, x 12, x 17$ & $50 \%$ & $30 \%$ & Não \\
\hline 4.4 .4 & $\begin{array}{l}\text { Realizar acompanhamento } \\
\text { do projeto de investimento } \\
\text { ao longo do tempo e dos } \\
\text { seus componentes que } \\
\text { foram agregados ao longo } \\
\text { da vida de uma máquina }\end{array}$ & $\mathrm{J}$ & FMEA & $x 20$ & $80 \%$ & Não & Não \\
\hline 4.4 .5 & $\begin{array}{l}\text { Planejar o projeto do } \\
\text { produto formalmente, } \\
\text { exigindo-se o cumprimento } \\
\text { das etapas. Utilizar os } \\
\text { diários de bordo na } \\
\text { determinação dos tempos } \\
\text { operacionais }\end{array}$ & 0 & FMEA & $x 3, x 4, x 8, x 9$ & $70 \%$ & Não & Não \\
\hline 4.4 .6 & $\begin{array}{l}\text { Criação de check-list } \\
\text { para validação de etapas } \\
\text { anteriores à aprovação da } \\
\text { diretoria }\end{array}$ & $0, P$ & FMEA & $\begin{array}{c}x 1, x 2, x 10, x 13, \\
x 14, x 16\end{array}$ & Não & Não & $\begin{array}{c}\text { Redução de } 50 \% \text { da } \\
\text { taxa de retrabalho }\end{array}$ \\
\hline \multirow[t]{2}{*}{ 4.4.7 } & \multirow{2}{*}{$\begin{array}{l}\text { Aplicação do Q-ROC } \\
\text { (Quick Reponse Office } \\
\text { Cell) e de trabalhadores } \\
\text { multifuncionais }\end{array}$} & $\begin{array}{l}\text { A, B, } \\
\text { C, D, E }\end{array}$ & $\begin{array}{l}\text { Diagrama } \\
\text { de espinha } \\
\text { de peixe }\end{array}$ & \multirow[t]{2}{*}{$x 7, x 8, x 13, x 15$} & $10 \%$ & $10 \%$ & Não \\
\hline & & Nenhuma & Nenhuma & & Não & Não & $\begin{array}{l}\text { Modificação do } \\
\text { layout }\end{array}$ \\
\hline 4.4 .8 & $\begin{array}{l}\text { Participação de uma } \\
\text { pessoa da Engenharia } \\
\text { de Processo durante a } \\
\text { realização da etapa }\end{array}$ & $\mathrm{D}$ & $\begin{array}{l}\text { Diagrama } \\
\text { de espinha } \\
\text { de peixe }\end{array}$ & $x 3$ & $70 \%$ & $5 \%$ & Não \\
\hline 4.4 .9 & $\begin{array}{c}\text { Realizar a execução } \\
\text { das etapas conforme } \\
\text { previsto no mapeamento } \\
\text { de processo }\end{array}$ & Todas & $\begin{array}{l}\text { Mapa de } \\
\text { processo }\end{array}$ & $x 10, x 11, x 19$ & Não & Não & $\begin{array}{l}\text { Definição do caminho } \\
\text { crítico e etapas } \\
\text { sendo realizadas em } \\
\text { paralelo com outras }\end{array}$ \\
\hline
\end{tabular}

Fonte: Elaborado pelos autores.

da empresa mostram que é de 5\% a quantidade de novos itens lançados em um ano.

\subsubsection{Criar procedimentos para levantar critérios de rateio com as áreas envolvidas no processo}

Essa recomendação teve origem durante a elaboração do FMEA, caracterizando-se uma ação de melhoria. Consiste na criação de procedimentos para o levantamento dos critérios de rateio junto às áreas envolvidas na orçamentação da empresa e, também, na criação de uma base histórica dos critérios adotados em meses anteriores. Estima-se que essa melhoria tenha como impacto uma redução de 30\% no tempo de agregação de valor e de 50\% do tempo de não agregação de valor da etapa ' $G$ ' do processo de orçamentação. Com essa melhoria, espera-se combater as seguintes causas do longo lead time identificadas na Figura 6: i) falta de integração entre as áreas envolvidas no processo (x8); ii) falta de procedimento detalhado para execução (x10); iii) falta de parâmetros para negociação (x12); iv) conflito de interesse (falta de alinhamento - x17). 


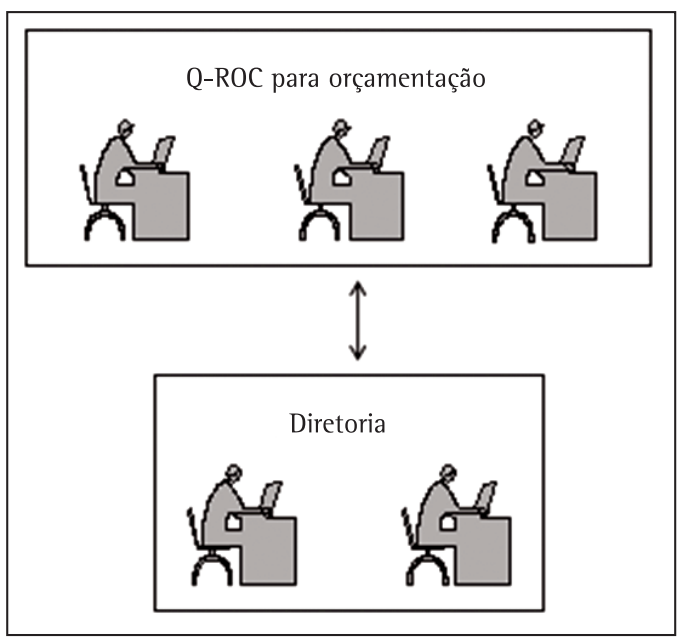

Figura 7. Célula Q-ROC para orçamentação. Fonte: Elaborado pelos autores.

\subsubsection{Acompanhar o projeto de investimento ao longo do tempo e dos seus componentes}

Com a elaboração do FMEA, observou-se também a possibilidade dessa recomendação como ação de melhoria, atacando a causa falta de monitoramento do plano de investimento (x20). Trata-se da realização de um acompanhamento do projeto de investimento ao longo do tempo e dos componentes que foram agregados ao longo da vida de uma máquina. A adoção dessa melhoria pode reduzir em torno de $80 \%$ o tempo de não agregação de valor no levantamento de depreciação prevista (etapa 'J' do processo de orçamentação).

\subsubsection{Planejar o projeto do produto formalmente}

Consiste na exigência de que o projeto do produto seja feito de maneira formal, com o cumprimento das tarefas exigidas e da utilização dos diários de bordo na determinação dos tempos operacionais de produção. Essa ação de melhoria foi identificada no decorrer da elaboração do FMEA e com ela espera-se reduzir $70 \%$ do tempo de não agregação de valor da etapa ' 0 ' do processo de orçamentação e eliminar/ amenizar as causas 'x3', 'x4', 'x8' e 'x9'.

\subsubsection{Criação de check-list para validação de etapas anteriores à aprovação da diretoria}

Essa recomendação também surgiu durante a elaboração do FMEA. Trata-se de uma ação de melhoria, e consiste na criação de um check-list para validação das etapas anteriores à avaliação da diretoria (etapa 'P'). Isso poderá garantir a obtenção formal do comprometimento das áreas envolvidas com o processo de orçamentação, impactando nas causas presentes no Quadro 8 (x1, x2, x10, x13, x14, x16).

\subsubsection{Aplicação do Q-ROC e de trabalhadores multifuncionais}

0 propósito do Q-ROC (Quick Response Office Cell) é a criação de células de escritório implementadas em ambiente de trabalho administrativo. Como já exposto, o diagrama de espinha de peixe elencou algumas potenciais causas do alto lead time do processo de orçamentação. A aplicação do Q-ROC e de trabalhadores multifuncionais possibilita atacar as causas ' $x 7$ ', ' $x 8$ ', ' $x 13$ ' e ' $x 15$ ', uma vez que a origem dessas causas converge para o princípio organizacional do QRM 'POE 7' (Quadro 2). De acordo com Suri (1998), a aplicação do Q-ROC em ambientes administrativos tem como consequência a criação de trabalhadores multifuncionais, com maior poder de decisão e mais integrados entre si. Sendo assim, a criação de células Q-ROC atacaria as causas potenciais do alto lead time, já mencionadas, e diminuiria $10 \%$ do tempo de agregação de valor e de não agregação de valor para as etapas de ' $A$ ' até 'E', uma vez que estas são as etapas influenciadas pelas causas potenciais levantadas.

A aplicação de células Q-ROC implica, também, na alteração do layout. A Figura 7 mostra como seria a célula Q-ROC.

Quando comparada a Figura 7 com a Figura 2 da seção 4 (figura que mostra o layout atual das áreas envolvidas com o processo de orçamentação), observa-se a inexistência das seguintes áreas: comercial, planejamento da produção e orçamento e custos. Isso se deve ao fato de que, com a implantação das células Q-ROC, os trabalhadores serão multifuncionais e dedicados às atividades de orçamentação. A célula foi dimensionada da seguinte forma: a partir dos resultados contidos no Quadro 9 da seção 4.5.1 (resultados da simulação do cenário de melhorias), é possivel notar que houve uma diminuição do lead time total de 38,1\%. Portanto, houve um ganho de aproximadamente 39 dias de 9 horas cada um, ou seja, houve um ganho de aproximadamente 350 horas de mão de obra direta envolvida no processo de orçamentação. Isso permitiu que a célula Q-ROC fosse dimensionada com apenas três pessoas dedicadas exclusivamente ao processo de orçamentação. Uma observação importante é que inicialmente o processo de orçamentação era feito por sete pessoas (excluindo-se os dois diretores), mas estas pessoas não eram dedicadas exclusivamente a este processo. 


\subsubsection{Participação de uma pessoa da engenharia de processo}

Uma causa potencial do alto lead time, levantada a partir do diagrama de espinha de peixe, é a ausência de parâmetros de roteiro e lista técnica (x3). Tal causa potencial pode ser eliminada com a participação de uma pessoa da área de Engenharia de Processo durante a realização da etapa 'D' do processo de orçamentação. Tal recomendação poderá reduzir em 5\% o tempo de agregação de valor e em 70\% o tempo de não agregação de valor dessa atividade.

\subsubsection{Executar as etapas conforme previsto no mapeamento de processo}

A seção 4.2.2 expôs o mapa do processo de orçamentação por meio da Figura 4. Com esse mapeamento observou-se que as atividades da orçamentação podem ser realizadas em paralelo. Isso contribuirá significativamente para a redução do lead time, uma vez que o processo de orçamentação atual é feito de maneira sequencial. Houve, também, a definição do caminho crítico para o processo em questão. Dessa forma, essa sugestão auxilia a combater as seguintes causas: $i$ ) falta de procedimento detalhado para a execução (x10); ii) disponibilização de recursos humanos (x11); iii) disponibilização de tempo (x19).

\subsection{Análise dos resultados esperados}

Nesta seção, há a explicitação dos resultados esperados com a implantação das melhorias propostas. Tais resultados esperados foram calculados por meio do uso de simulação computacional e benchmarking interno.

\subsubsection{Simulação}

Mais uma vez utilizou-se o software Arena ${ }^{\circledR}$. Os resultados obtidos por meio da simulação do cenário que contém as melhorias propostas podem ser observados no Quadro 9. Caso haja a implantação das melhorias propostas, haverá uma redução de: i) 39,1\% do tempo de agregação de valor; ii) 37,9\% do tempo de não agregação de valor; iii) 38,1\% do lead time total.

\subsubsection{Benchmarking interno}

O benchmarking interno foi utilizado para comparar a situação atual do processo de orçamentação com a situação desse processo após uma possível implementação das melhorias propostas. Dentre as três situações de comparação, duas representam casos extremos, denominadas de "Best-Case Performance" (melhor desempenho possível) e "Worst-Case Performance" (pior desempenho possivel). A terceira possibilidade é um caso intermediário entre os dois extremos e que representa o "Practical Worse-Case (pior caso prático possível).

Para elaboração do benchmarking interno, foi necessário conhecer alguns dados, a saber: taxa de produção do gargalo (tg) de 45 itens/dia (que representa a quantidade de itens diários orçados na atividade gargalo do processo de orçamentação), o lead time sem filas (Lsf) de 28 dias (tempo para finalizar o orçamento de um item, passando por todas as etapas do processo de orçamentação, porém considerando apenas o tempo de processamento) e Nível Crítico de estoque em processo (Wo) de 1.260 itens (que representa a multiplicação de tg por Lsf).

Foi gerado um novo benchmarking interno considerando as melhorias propostas. Como pode ser visto na Figura 8, o processo de orçamentação inicialmente apresentava em média um estoque em processo (WIP) de 1800 itens, apresentando um lead time de aproximadamente 78 dias. 0 lead time reduziu para aproximadamente 48 dias, para um WIP de 1800 itens, após as melhorias propostas. Dessa forma, a situação do processo de orçamentação sai da denominada "região ruim" para a chamada "região boa", nas palavras de Hopp e Spearman (2008).

\section{Análise dos princípios do QRM utilizados na empresa}

Pode-se verificar que, no estudo de caso realizado, muitos dos princípios do QRM para o escritório (vistos na seção 2) foram utilizados neste trabalho. Com relação aos princípios organizacionais, para a

Quadro 9. Resultados da simulação.

\begin{tabular}{|c|c|c|c|}
\hline Dados & $\begin{array}{c}\text { Situação Atual } \\
\text { (dias) }\end{array}$ & $\begin{array}{c}\text { Situação após Melhorias } \\
\text { Propostas (dias) }\end{array}$ & $\begin{array}{c}\text { Redução } \\
\text { (\%) }\end{array}$ \\
\hline Tempo de agregação de valor & 29,1 & 17,7 & 39,1 \\
\hline Tempo de não agregação de valor & 49,3 & 30,6 & 37,9 \\
\hline Lead time total & 78,4 & 48,5 & 38,1 \\
\hline
\end{tabular}

Fonte: Elaborado pelos autores. 


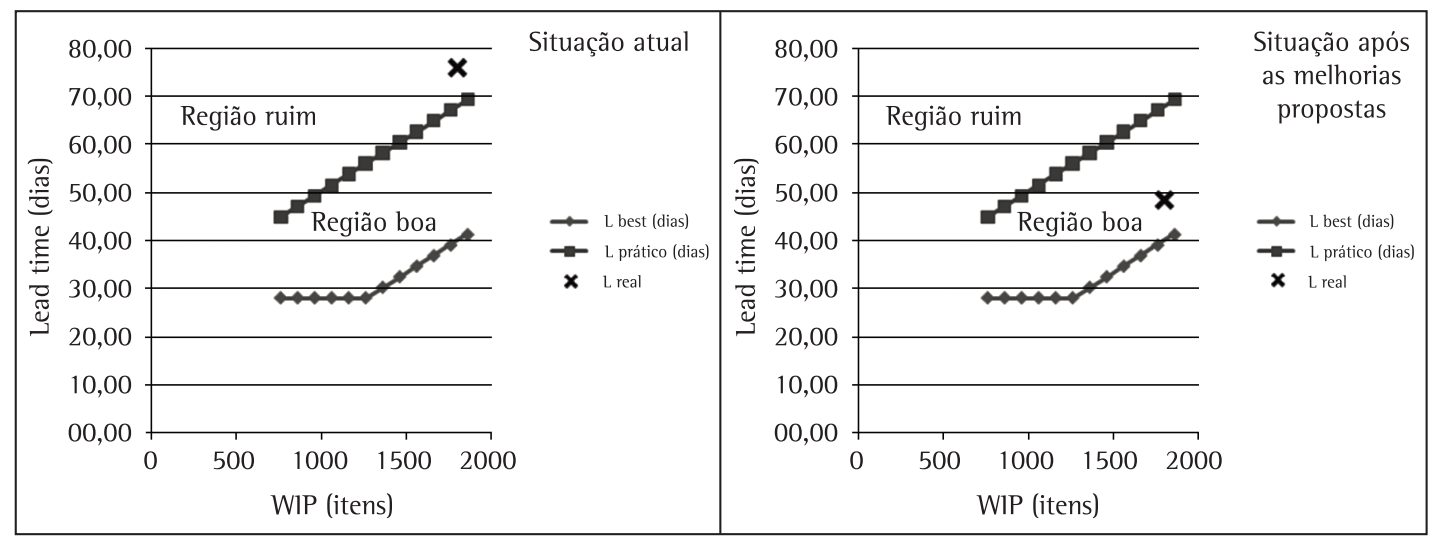

Figura 8. 0 benchmarking interno atual e do cenário de melhoria (Lead Time x WIP). Fonte: Elaborado pelos autores.

identificação do FTMS (POE 5) - que é o processo de orçamentação de 1800 itens da empresa de materiais de escrita - focou-se o segmento de mercado de materiais de escrita (POE 1); determinou-se o produto do processamento no escritório para este segmento (POE 2), constituído pelo orçamento anual; foram identificadas as atividades no escritório necessárias para se chegar a este produto (POE 3), sendo essas atividades especificadas no Quadro 7. Verificou-se a impossibilidade de implantar o princípio quatro (POE 4) devido à característica sequencial e à relação de dependência entre as atividades do processo de orçamentação.

Os esforços iniciais do QRM no FTMS (POE 6) envolveram a demarcação das fronteiras do FTMS, que inicia na atividade de levantamento do volume de faturamento por item e finaliza na realização da carga dos dados no sistema e gravação dos custos planejados. Além disso, nessa etapa foram identificadas as características de cada atividade (tarefa a ser realizada, relacionamento entre as atividades, tempo de execução, funcionários envolvidos, verificação da existência de procedimentos padronizados, relevância da atividade) e os recursos materiais e patrimoniais envolvidos, para assim redimensionar as atividades e criar a célula no escritório Q-ROC (POE 7).

Identificou-se então a possibilidade de reprojetar/ repensar algumas tarefas (POE 8), visando maior redução do lead time. Tais pontos são explicitados na subseção 4.4, dentre os quais está a proposta de melhoria na atividade de levantamento da depreciação prevista (subseção 4.4.4). Nesta, notou-se que poderia ser realizado o acompanhamento do projeto de investimento ao longo do tempo e dos componentes que foram agregados ao longo da vida de uma máquina, o que impactaria em uma redução de $80 \%$ no tempo de não agregação de valor da tarefa.
Preocupou-se, também, com o fornecimento de recursos e suporte para garantir o fluxo rápido dos trabalhos (POE 9). Assim, dentre as propostas significativas (vide subseção 8.2), está o compartilhamento de informações necessárias para a realização do orçamento e a criação de uma equipe multifuncional dedicada totalmente à atividade de orçamentação no período em que é necessária a realização desse processo. Ao término do processo de orçamentação, esses funcionários são alocados novamente as suas funções cotidianas.

Devido ao grau de importância e impacto do orçamento na organização, não foi possível eliminar todos os sistemas de controles tradicionais no processo analisado (POE 10), no qual foi mantida a conferência/ aprovação do orçamento realizado pela diretoria. Ademais, o princípio 11 (POE 11) não foi implantado, pois não havia a necessidade de integrar a célula Q-ROC com células de manufatura, devido às características do processo de orçamentação.

Quanto aos princípios para manuseio e gestão da informação, buscou-se implementar a regra 'no máximo uma' (PMGl 1), eliminando os fluxos e tarefas redundantes e aplicando o conceito de trabalhadores multifuncionais. Durante a aplicação desse princípio, os princípios PMGl 2 e PMGl 3 foram considerados, com a preocupação de se reexaminar as reais necessidades de informações para execução do processo de orçamentação e garantir o rápido acesso e local à informação. Esses pontos podem ser verificados nas Figuras 2 e 7, nas quais são expostos, respectivamente, os layouts, o atual e após a criação da célula Q-ROC.

As tecnologias utilizadas para facilitar a comunicação foram o e-mail interno, Internet e banco de dados compartilhados (PMGl 4). Além disso, a empresa estudada já possuía uma preocupação em 
investir em compatibilidade de sistemas de informação (PMGl 5), sendo os principais sistemas utilizados: ERP (Enterprise Resource Planning) e ferramentas específicas que auxiliam na construção do Bl (Bussiness Intelligence), como o Data Warehouse e ferramentas OLAP (Online Analytical Processing).

Durante a realização desta pesquisa, os oito princípios que exploram a dinâmica dos sistemas para o escritório também foram levados em conta. A utilização dos recursos envolvidos com o processo de orçamentação foi reduzida (PSDE 1). Para tanto, durante a criação da célula Q-ROC, foram alocados funcionários dedicados exclusivamente para a orçamentação. Além disso, a medida de desempenho destes foi baseada na redução de lead time (PSDE 2), sendo que o princípio de uso da junção de recursos e filas únicas foi utilizado somente quando possível flexibilizar os recursos (PSDE 4).

Em busca da redução da variabilidade no escritório (PSDE 3), houve a proposta de padronização de roteiros, de procedimentos e eliminação de retrabalhos. Tais necessidades foram verificadas ao realizar o FMEA (Análise de Modo e Efeitos de Falha) do processo.

Dentre as atividades que podem ser realizadas em paralelo, segundo o PSDE 5, estão: 'Calcular a necessidade de recursos produtivos (mão de obra e máquina)'; 'Levantar consumo previsto com Energia+Água+Esgoto’; 'Levantar gastos previstos com compra de matéria-prima’. O Mapa do processo de orçamentação, que mostra o relacionamento entre as atividades do processo, dentre outras informações, pode ser observado na Figura 4 da subseção 4.4.2. Devido às características do processo em estudo, os princípios PSDE 6, PSDE 7 e PSDE 8 foram adaptados. Houve o uso de softwares de simulação para o estudo da situação atual da orçamentação e para estudo das melhorias propostas com uso da abordagem QRM.

Quadro 10. Princípios utilizados em cada etapa da pesquisa.

\begin{tabular}{|c|c|}
\hline Etapa & Princípios \\
\hline $\begin{array}{c}\text { Definição do } \\
\text { Problema }\end{array}$ & POE 1, POE 2, POE 3, POE 5 e POE 6 \\
\hline $\begin{array}{c}\text { Coleta e } \\
\text { Análise de Dados }\end{array}$ & PMGl 2 e PMGl 3 \\
\hline $\begin{array}{c}\text { Propostas de } \\
\text { Melhorias }\end{array}$ & $\begin{array}{c}\text { POE 9, POE 10, PMGl 1, PMG1 4, PSDE 1, } \\
\text { PSDE 3, PSDE 5, PSDE 6, PSDE 7 e PSDE 8 }\end{array}$ \\
\hline $\begin{array}{c}\text { Análise dos } \\
\text { Resultados Esperados }\end{array}$ & POE 7, POE 8, PMGl 5, PSDE 2 e PSDE 4 \\
\hline
\end{tabular}

Quadro 11. Resumo dos ganhos obtidos com o projeto.

\begin{tabular}{|c|c|c|}
\hline Variável & Antes & Depois \\
\hline Lead time (conforme a simulação) & 78,4 dias & 48,5 dias \\
\hline № de funcionários envolvidos & 7 & 3 \\
\hline
\end{tabular}

A análise foi procedida com o intuito de reduzir os tamanhos de lotes nas operações realizadas, liberação das tarefas somente quando houver capacidade disponível e flexibilização de funcionários para realização das atividades do processo em questão.

O Quadro 10 apresenta quais princípios do QRM guiaram a condução de cada etapa da pesquisa.

\section{Considerações finais}

Estudos mostram, segundo Suri (1998, 2010), que as atividades realizadas no escritório podem ser responsáveis por mais da metade do lead time total em uma empresa. Apesar desta importância, o escritório é uma atividade que não tem a atenção que deveria ter. A grande maioria das abordagens de gestão da produção considera o escritório uma atividade secundária, não trazendo ferramentas para esta importante área do negócio. Apesar de seu foco no chão de fábrica, o QRM também apresenta princípios e ferramentas para a redução de lead time nas atividades de escritório.

0 presente trabalho objetivou apresentar uma proposta para a implementação do QRM para redução do lead time no processo de orçamentação de uma empresa que fabrica materiais de escrita. Os resultados esperados com a implantação das propostas de melhoria apontam uma redução de $38,1 \%$ no lead time total do processo de orçamentação da empresa estudada, logo, o objetivo almejado na pesquisa foi atingido.

Ressalta-se que as recomendações foram realizadas considerando-se um primeiro ciclo de melhoria. Portanto, há a possibilidade de reduzir ainda mais o lead time da orçamentação nos próximos esforços de melhoramento do processo.

Durante a realização dessa pesquisa, preocupou-se com a manutenção da confiabilidade das informações geradas na orçamentação, uma vez que é por meio desta que a diretoria da empresa se compromete com seus investidores em relação ao desempenho do período, tanto em termos de lucratividade como também em gestão de capital.

0 resumo dos ganhos obtidos com o projeto pode ser observado no Quadro 11. Nota-se que o lead time total atual é de 78,4 dias e após a implantação das melhorias via simulação computacional, o lead time reduziu para 48,5 dias. Além disso, o número de funcionários envolvidos no processo de orçamentação era de sete e foi reduzido para três.

Esse artigo contribui para maior divulgação e compreensão da abordagem QRM e de seus benefícios, como a redução do lead time das operações empresariais. Além disso, desperta a atenção para a 
realização de pesquisas com essa temática e com aplicações em operações de escritório. Destaca-se que os resultados do presente trabalho podem também ser obtidos por empresas com características similares que apliquem a abordagem QRM.Como pesquisas futuras, sugere-se efetuar pesquisa-ação com o intuito de implantar as recomendações na prática empresarial, utilizando ferramentas de priorização de ações, por exemplo, matriz causa e efeito e matriz esforço $\mathrm{x}$ impacto, e controlar os resultados concretos do primeiro esforço de melhoria.

\section{Referências}

AGUIAR, S. Integração das Ferramentas da Qualidade ao PDCA e ao Programa Seis Sigma. Nova Lima: INDG, 2006.

BERTO, R. M. V. S.; NAKANO, D. N. A produção científica nos anais do encontro nacional de engenharia de produção: um levantamento dos métodos e tipos de pesquisa. Produção, v. 9, n. 2, p. 65-75, 2000. http://dx.doi. org/10.1590/S0103-65131999000200005

BERTO, R. M. V. S.; NAKANO, D. N. Metodologia da pesquisa e a engenharia de produção.In: ENCONTRO NACIONAL DE ENGENHARIA DE PRODUÇÃO - ENEGEP, 28.; INTERNATIONAL CONGRESS OF INDUSTRIAL ENGINEERING - ICIE, 4., 1998, Niterói. Anais...Niterói: UFF/ABEPRO, 1998. 1 CD-ROM.

BERTOLINI, M. et al. Lead time reduction through ICT application in the footwear industry: A case study. International Journal Production Economics, v. 110, p. 198-212, 2007. http://dx.doi.org/10.1016/j. ijpe.2007.02.016

BOTTANI, E.; RIZZI, A. An adapted multi-criteria approach to suppliers and products selection: an application oriented to lead-time reduction. International Journal Production Economics, v. 111, p. 763-781, 2008. http://dx.doi. org/10.1016/j.jpe.2007.03.012

BRIAN, H. F. ls your office as lean as your production line? Manufacturing Engineering, v. 139, n. 3, 2007.

BUSSAB, W. 0.; MORETTIN, P. A. Estatística Básica. 5. ed. São Paulo: Saraiva, 2002.

CAMPOS, V. F. Gerenciamento da Rotina do Trabalho do Dia-a-Dia. 8. ed. Nova Lima: INDG, 2004.

ERICKSEN, P. D.; STOFLET, N. J.; SURI, R. Manufacturing Critical-path Time (MCT): The QRM Metric for Lead time. Technical Report, Center for QRM, Wisconsin-Madison, 2007.

FAHIMNIA, B.; MARIAN, R.; MOTEVALLIAN, B. Analysing the hindrances to the reduction of manufacturing lead-time and their associated environmental pollution. International Journal of Environmental Technology and Management, v. 10, n.1, p. 16-25, 2009. http://dx.doi. org/10.1504/1JETM.2009.021574

FERNANDES, N. 0.; CARMO-SILVA, S. Generic POLCA: A production and materials flow control mechanism for quick response manufacturing. International Journal of Production Economics, v. 104, n. 1, p. 74-84, 2006. http://dx.doi.org/10.1016/j.ijpe.2005.07.003

FORRESTER, J. W. Industrial dynamics. Cambridge: Produtivity Press, 1961.
GITMAN, L. J. Princípios de Administração Financeira. 10. ed. São Paulo: Pearson, 2004.

GODINHO FILHO, M.; UZSOY, R. Efeito da redução do tamanho de lote e de programas de Melhoria Contínua no Estoque em Processo (WIP) e na Utilização: estudo utilizando uma abordagem híbrida System Dynamics - Factory Physics. Produção, v. 19, n.1, p. 214-229, 2009.

HERKOMMER, J.; HERKOMMER, 0. Lean Office System. Zeitschrift fuer Wirtschaftlichen Fabrikbetrieb, v. 101, n. 6, p 378-381, 2006.

HOPP, W. J.; SPEARMAN, M. L. Factory Physics: Foundation of Manufacturing Management. 3. ed. International Edition, McGrawHill/lrwin, 2008.

LAW, A. M.; KELTON, W. D. Simulation modeling \& analysis. 2nd ed. New York: McGraw Hill Inc., 1991.

LENG, M.; PARLAR, M. Lead-time reduction in a two-level supply chain: Non-cooperative equilibria vs. coordination with a profit-sharing contract. International Journal Production Economics, v. 118, p. 521-544, 2009. http:// dx.doi.org/10.1016/j.ijpe.2009.01.002

MARTINS, E. Contabilidade de Custos. 9. ed. São Paulo: Atlas, 2006.

MASON-JONES, R.; TOWILL, D. R. Total cycle time compression and the agile logistic network. International Journal Production Economics, v. 62, p. 61-73, 1999. http://dx.doi.org/10.1016/S0925-5273(98)00221-7

OSBORN, A. F. Applied imagination: Principles and procedures of creative problem solving. 3. ed. rev. New York: Charles Scribner's Sons, 1963.

OUYANG, L-Y.; CHUANG, B-R.; LIN, Y-J. The inter-dependent reductions of lead time and ordering cost in periodic review inventory model with backorder price discount. International Journal of Information and Management Sciences, v. 18, n. 3, p. 195-208, 2007.

PADOVEZE, C. L. Contabilidade Gerencial: um enfoque em sistema de informação contábil. 5. ed. São Paulo: Atlas: 2007.

PARVEEN, M.; RAO, T. V. V. L. N. Managing quality improvement, setup cost and lead time reductions in a just-in-time integrated inventory model. International Journal of Information Systems and Change Management, v. 3, n. 2, p. 147-156, 2008. http://dx.doi. org/10.1504/IJISCM.2008.020692

PATTON, M. Q. Qualitative evaluation and research methods. Newburry Park, 1990.

PERRY, J. H. Lead time management: private and public sector practices. Journal of Purchasing and Materials Management, v. 26, p. 2-7, 1990.

PEZEIRO, A. Seis Sigma: Ferramentas e Estatística Básica para Melhoria dos Processos. Seta Desenvolvimento gerencial, 2005.

PORTER, A. M. Unlocking leadtimes. Purchasing, p. 34-37, 2003.

SAES, E. V.; GODINHO FILHO, M. Lean Manufacturing e Quick Response Manufacturing: Análise Comparativa. In: SIMPÓSIO DE ENGENHARIA DE PRODUÇÃO - SIMPEP,15., 2008, Bauru. Anais... UNESP, 2008.

SCHMENNER, R. W. Time Based Competition: The Next Battleground in American Manufacturing. In: BLACKBURN, J. D. (Ed.). Speed and productivity. Homewood: Irwin, 1991. p. 102-120. 
SELLITTO, M. A.; BORCHARDT, M.; PEREIRA, G. M. Medição de tempo de atravessamento e inventário em processo em manufatura controlada por ordens de fabricação. Produção, v. 18, n. 3, p. 493-507, 2008.

SONG, H-M.; MING, S-H. A vendor-buyer stochastic inventory model with lead time reduction in supply chain. Proceedings... In: INTERNATIONAL CONFERENCE ON MACHINE LEARNING AND CYBERNETICS, 5., 2006, Dalian. Proceedings... 2006. p. 13-16.

SURI, R. It's About Time: The Competitive Advantage of Quick Response Manufacturing. Productive Press, 2010. http://dx.doi.org/10.1201/EBK1439805954

SURI, R. Quick Response Manufacturing: A companywide Approach to Reducing Lead Times. Productive Press, 1998.

SURI, R. Rapid modeling: how it assists manufacturing competitiveness. In: WINTER SIMULATION CONFERENCE, 1989, Baltimore. Proceedings.. Baltimore, 1989. p. 80-83.

TAPPING, D; SHUKER, T. Value stream management for the lean office: 8 steps to planning, mapping, and sustaining lean improvements in administrative areas. New York: Productivity Press, 2003.

TERSINE, R. J.; HUMMINGBIRD, E. A. Lead-time reduction: the search for competitive advantage.
International Journal of Operations \& Production Management, v. 15, n. 2, p. 8-18, 1995. http://dx.doi. org/10.1108/01443579510080382

TREVILLE, S.; SHAPIRO, R. D.; HAMERI, A-P. From supply chain to demand chain: the role of lead time reduction in improving demand chain performance. Journal of Operations Management, v. 21, p. 613-627, 2004. http:// dx.doi.org/10.1016/j.jom.2003.10.001

TREVILLE, S. Using RMT to make kaizen work more effectively. APICS - The performance advantage, October 1994.

UNIVERSITY OF WISCONSIN. Centrer of Quick Response Manufacturing - QRM. Disponivel em: <http://www. engr.wisc.edu/centers/cqrm/projects.htm>. Acesso em: 28 ago. 2009.

WALPOLE, R. E. et al. Probabilidade \& Estatística para engenharia e ciências. 8. ed. Rio de Janeiro: Pearson, 2009.

WESTWOOD, J. O plano de marketing. São Paulo: Makron Books, 1991.

WIETERS, C. D. Managing supplier leadtime. Journal of Purchasing and Materials Management, v. 15, p. 2-7, 1979.

YIN, R. K. Case study reseach: design and methods. Newbury Park: Sage Publications, 1994.

\title{
Proposal for implementation of the approach Quick Response Manufacturing (QRM) to reduce lead-time in office operations
}

\begin{abstract}
The efficient and effective management of lead-time can create competitive advantages for companies. One approach that has the preoccupation to reduce lead-time is the Quick Response Manufacturing. The aim of this paper is to propose the implementation of principles and techniques of QRM for lead-time reduction in the budgeting process of an enterprise of writing materials (general writing) located in Brazil. To this end, the theoretical-conceptual research and case study were used as research procedures. It was found that the studied company could obtain significant benefits by adopting this approach. The expected results through the implementation of the proposal show a decrease of $38.1 \%$ in the total lead-time of the budgeting process of the company studied. This paper contributes to a greater dissemination and understanding of the QRM approach and its benefits.
\end{abstract}

\section{Keywords}

Quick response manufacturing. Lead-time. Office operations. Budgeting. 